University of Louisville

ThinkIR: The University of Louisville's Institutional Repository

$12-2020$

\title{
Language ability and concurrent predictors of pragmatic communication in children with williams syndrome or $7 q 11.23$ duplication syndrome.
}

Amanda G. Harmon

University of Louisville

Follow this and additional works at: https://ir.library.louisville.edu/etd

Part of the Child Psychology Commons, and the Developmental Psychology Commons

\section{Recommended Citation}

Harmon, Amanda G., "Language ability and concurrent predictors of pragmatic communication in children with williams syndrome or 7q11.23 duplication syndrome." (2020). Electronic Theses and Dissertations. Paper 3531.

https://doi.org/10.18297/etd/3531

This Doctoral Dissertation is brought to you for free and open access by ThinkIR: The University of Louisville's Institutional Repository. It has been accepted for inclusion in Electronic Theses and Dissertations by an authorized administrator of ThinkIR: The University of Louisville's Institutional Repository. This title appears here courtesy of the author, who has retained all other copyrights. For more information, please contact thinkir@louisville.edu. 


\title{
LANGUAGE ABILITY AND CONCURRENT PREDICTORS OF \\ PRAGMATIC COMMUNICATION IN CHILDREN WITH \\ WILLIAMS SYNDROME OR 7Q11.23 DUPLICATION SYNDROME
}

$$
\text { By: }
$$

Amanda G. Harmon

B. S., The Pennsylvania State University, 2006

M.S., The Pennsylvania State University, 2008

M.S., University of Louisville, 2011

\author{
A Dissertation \\ Submitted to the Faculty of the \\ College of Arts and Sciences \\ of the University of Louisville \\ in Partial Fulfillment of the Requirements \\ for The Degree of \\ Doctor of Philosophy \\ In Experimental Psychology \\ Department of Psychological and Brain Sciences \\ University of Louisville \\ Louisville, Kentucky
}

December 2020 
Copyright 2020 by Amanda G. Harmon

All rights reserved 



\section{LANGUAGE ABILITIES AND CONCURRENT PREDICTORS OF \\ PRAGMATIC COMMUNICATION IN CHILDREN WITH \\ WILLIAMS SYNDROME OR 7Q11.23 DUPLICATION SYNDROME}

By:

Amanda G. Harmon

B. S., The Pennsylvania State University, 2006

M.S., The Pennsylvania State University, 2008

M.S., University of Louisville, 2011

A dissertation approved on

December 11, 2020

by the following Dissertation Committee:

Carolyn B. Mervis, Ph.D.

Dissertation Director

John R. Pani, Ph.D.

Cara H. Cashon, Ph.D.

Keith B. Lyle, Ph.D.

Guy O. Dove, Ph.D. 


\section{DEDICATION}

To my husband, Billy, without whom this dissertation would never have been completed, much less started. It was almost 30 years ago that I left college to marry you. You made a promise to me that when the time was right, you would encourage me to go back and finish my degree. When that time came, you kept your promise and motivated me, influenced me, and persuaded me until I inevitably returned to school - some 14

years later. This is a small thank you for all the times that you prayed with me and for me, the times you encouraged me and endured with me as I finished each milestone. Another 15 years later and I have finished. Behind this long-awaited degree, stands your inordinate support. Thank you for believing I could do it and for keeping your promise. Ephesians 5:25

Husbands, love your wives, just as Christ also loved the church and gave Himself up for her. 


\section{ACKNOWLEDGEMENTS}

To my husband Billy, thank you so much for all you have done, I could have never made it this far without your encouragement.

I am thankful for my children Hannah, Ashlynn, and Joshua who each spent time by my side as we did schoolwork together. I am grateful for the many ways you have each prayed, supported, and encouraged me in this process. To my youngest, Arianna, I am thankful for the fun laughs we had this last semester while you were learning the alphabet and attempting to name each letter in this work.

Mom and Dad, thank you for teaching me to never stop learning and encouraging me to work hard.

Nana and Paw Paw Broom, thank you so much for the prayers and support through the years.

I am extremely grateful for Ms. Gail and the many practical ways you helped me the last few years.

I extend sincere gratitude to Dr. Carolyn Mervis for her teaching, support, and guidance along the way.

I extend heartfelt gratitude to my entire committee, Dr. Carolyn Mervis, Dr. John Pani, Dr. Cara Cashon, Dr. Keith Lyle, and Dr. Guy Dove, who generously gave of their time to help me see this to the end.

I am appreciative to the children with Williams syndrome and 7q11.23 duplication syndrome and their families for their continued participation in our research.

I am thankful for all the current and past members of the Neurodevelopmental Sciences Lab for their help with data collection and support through the process. 
I would like to express my gratitude to the funding agencies that provided the grants to Dr. Carolyn Mervis that supported this research: Williams Syndrome Association grants WSA 0104 and WSA 0111, Simons Foundation grant SFARI 238896, Eunice Kennedy Shriver National Institute of Child Health and Human Development grant R37 HD29957, and National Institute of Neurological Disorders and Stroke grant R01 NS35102. 


\begin{abstract}
LANGUAGE ABILITIES AND CONCURRENT PREDICTORS OF PRAGMATIC COMMUNICATION IN CHILDREN WITH WILLIAMS SYNDROME OR 7Q11.23 DUPLICATION SYNDROME
\end{abstract} Amanda G. Harmon

December 11, 2020

The present project examined the language abilities of children with two reciprocal neurogenetic disorders: Williams syndrome (WS), which is caused by a hemideletion of 26 - 28 genes on chromosome 7q11.23, and 7q11.23 duplication syndrome (Dup7), which results from an extra copy of the same 26 - 28 genes. Appraising the language of children with WS and Dup7 helps in understanding the communication difficulties they encounter. There were three research goals. The first was to determine the overall level of language and communication ability as measured by the Children's Communication Checklist-2 (CCC-2; Bishop, 2006) for each syndrome, relative to chronological age expectations. The second was to determine the pattern of relative strengths and weaknesses in language form and content, pragmatic communication, and autism-related behaviors for each syndrome. The final goal was to determine the concurrent predictors of pragmatic communication ability for each syndrome. The sample consisted of 247 children with WS (126 females, 121 males) aged $6.01-15.50$ years $(M=10.57$ years, $S D=2.96)$ and 56 children ( 28 females, 28 males $)$ with Dup7 aged $6.08-15.29$ years $(M=10.33$ years, $S D=2.82)$. 
Findings indicated that although there was considerable variability in overall language and communication ability, more than $60 \%$ of the children in each group met the CCC-2 criterion for language impairment. For most children, performance on the Language Form and Content scales was similar to performance on the Pragmatic Communication scales, a pattern characteristic of children in the general population.

Each syndrome demonstrated a pattern of relative strengths and weaknesses on the CCC-2 scales. For the Language Form and Content scales, children with WS evidenced a significant relative weakness on the Coherence scale in comparison to their performance on the Speech, Syntax, and Semantics scales. In contrast, children with Dup7 evidenced a significant relative weakness on the Speech scale. Furthermore, children with Dup7 earned a significantly lower scaled score than children with WS on the Speech scale. For the Pragmatic Communication scales, children with WS demonstrated relative weaknesses on the Initiation and Use of Context scales in comparison to the Scripted Language and Nonverbal Communication scales. Children with Dup7 demonstrated a partially overlapping pattern, with relative weaknesses on the Initiation and Nonverbal Communication scales. On the Autism-related scales, children with WS demonstrated a relative strength on the Social Relations scale compared to the Interests scale. Children with Dup7 demonstrated the opposite pattern.

For both syndromes, Pragmatic Communication ability was predicted by concurrent Language Form and Content ability, behavior and emotion regulation ability, and chronological age. For the WS group, sex also was a significant predictor. The effects of gene dosage on language and communication ability and implications of the findings for interventions designed to improve pragmatic communication abilities are discussed. 


\section{TABLE OF CONTENTS}

DEDICATION

ACKNOWLEDGEMENTS $\quad$ iv

ABSTRACT vi

LIST OF TABLES Ix

LIST OF FIGURES - xii

CHAPTER

I. INTRODUCTION 1

Children's Communicative Checklist 3

Factors Associated with Pragmatic Communication as

Measured by the CCC-2 4

$\begin{array}{ll}\text { Williams Syndrome (WS) } & 10\end{array}$

7q11.23 Duplication Syndrome (Dup7) 18

$\begin{array}{ll}\text { Present Dissertation } & 20\end{array}$

$\begin{array}{ll}\text { II. METHOD } & 22\end{array}$

III. RESULTS 32

$\begin{array}{ll}\text { IV.DISCUSSION } & 62\end{array}$

$\begin{array}{ll}\text { REFERENCES } & 73\end{array}$

$\begin{array}{lr}\text { CURRICULUM VITAE } & 89\end{array}$ 


\section{LIST OF TABLES}

1. Examples of CCC-2 Items Measuring Communication Difficulty or Strength as a

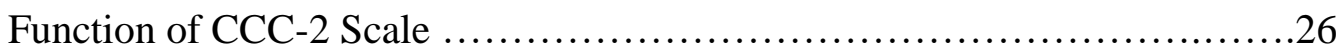

2. Descriptive Statistics for Parents' Ratings of the Performance of Children with Williams Syndrome and 7q11.23 Duplication Syndrome on the Children's Communication Checklist -2 ............................................ 33

3. Correlations between Scaled Scores on the CCC-2 Scales for Children with Williams Syndrome................................................. 35

4. Correlations between Scaled Scores on the CCC-2 Scales for Children with

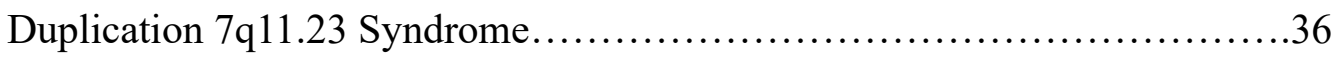

5. Descriptive Statistics for the CCC-2 Composite Standard Score and the Social Interaction Difference Index for Children with Williams Syndrome or 7q11.23

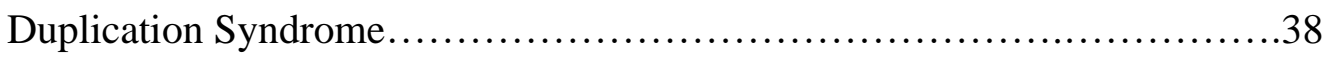

6. Descriptive Statistics for Parents' Ratings of the Performance of Children with Williams Syndrome or 7q11.23 Duplication Syndrome on the CCC-2 Language Form and Content Scales. .41

7. P values (Using Sidak Correction) and Cohen's d Values for Pairwise Comparisons of Scaled Scores on the CCC-2 Language Form and Content Scales as a Function of Syndrome 
8. P values (Using Sidak Correction) and Cohen's d Values for Pairwise Comparisons of Scaled Scores on the CCC-2 Language Form and Content Scales as a Function of Sex

9. Descriptive Statistics for Parents' Ratings of the Performance of Children with Williams Syndrome or 7q11.23 Duplication Syndrome on the CCC-2 Pragmatic Scales .49

10. P values (using Sidak Correction) and Cohen's d Values for Pairwise Comparisons of Scaled Scores on CCC-2 Pragmatic Scales as a function of Syndrome .51

11. Descriptive Statistics for the Parents' Ratings of the Performance of Children with Williams Syndrome or 7q11.23 Duplication Syndrome on the CCC-2 Autismrelated Scales 54

12. Descriptive Statistics for the Continuous Variables Included in the Regression Analyses: Children with Williams Syndrome

13. Correlations for Parent Ratings of the Performance of Children with Williams Syndrome on the Regression Variables 57

14. Multiple Regression Analysis Predicting Concurrent Pragmatic Communication Abilities for Children with Williams Syndrome as Measured by the Children's Communication Checklist -2 Mean Pragmatic Communication

Scaled Score .58

15. Descriptive Statistics for the Continuous Variables Included in the Regression Analyses: Children with 7q11.23 Duplication Syndrome 59 
16. Correlations for Parent Ratings of the Performance of Children with 7q11.23

Duplication Syndrome on the Regression Variables.......................66

17. Multiple Regression Analysis Predicting Pragmatic Concurrent Communication Abilities for Children with 7q11.23 Duplication Syndrome as Measured by the Children's Communication Checklist-2 Mean Pragmatic Communication Scaled

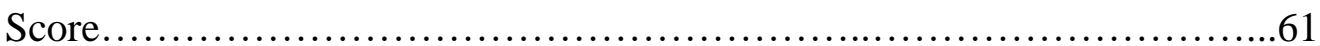




\section{LIST OF FIGURES}

1. Mean scaled scores for the CCC-2 Form and Content scales for children with Williams syndrome and children with 7q11.23 duplication syndrome. Error bars indicate the 95\% confidence intervals.

2. Mean scaled scores for children with Williams syndrome for the CCC-2 Form and Function scales as a function of sex. Error bars indicate the $95 \%$ confidence intervals

3. Mean scaled scores for the CCC-2 Pragmatic Communication scales for children with Williams syndrome and children with 7q11.23 duplication syndrome. Error bars indicate the $95 \%$ confidence intervals. .50

4. Mean scaled scores for the CCC-2 Autism-related scales for children with Williams syndrome and children with 7q11.23 duplication syndrome. Error bars indicate the 95\% confidence intervals. 


\section{CHAPTER I}

\section{INTRODUCTION}

The ability to use language effectively is beneficial in day-to-day social interactions and in building friendships. Bloom and Lahey (1978) define language as consisting of three essential elements: form (speech and grammar), content (semantics), and use (pragmatics). Pragmatic language requires that the speaker consider the situation and the relationships of those in the conversation and adjust his or her form and content accordingly (Washburn, 2011). An individual may be able to pronounce words correctly and use complex sentences with proper grammar. Nevertheless, when the speaker does not consider the social situation, these grammatically correct sentences may be misunderstood or misinterpreted. Background knowledge and social interaction skills need to be used to create understanding and meaning in conversation (Norbury \& Holloway, 2014). Thus, pragmatics includes an understanding of intent, discourse management skills, and following social dialogue rules, and involves both linguistic and non-linguistic communication (Landa, 2005). Findings from previous studies have identified relations between pragmatic communication ability and nonverbal ability, language form and content ability, sex, and executive function skills, although as reviewed below, the strength of these relations and the consistency with which they are found varies.

The ability to use socially appropriate language is challenging for individuals with a variety of disabilities. Reviews of the literature demonstrate that children who have 
language disorders or learning disorders (Lapadat, 1991) and children with emotional and behavioral disorders (Hyter, Rodgers-Adkinson, Self, Simmons, \& Jantz, 2001) have difficulty with pragmatic language, even though they do not have intellectual disability (ID). Children with autism spectrum disorder (ASD) have difficulty with pragmatic communication regardless of intellectual ability (Philofsky, Fidler, \& Hepburn, 2007; Volden \& Phillips, 2010), as do children with genetic disorders associated with ID or lower intellectual ability relative to family members, for example, children with Down syndrome (DS) (Laws \& Bishop, 2004; Lee et al., 2017), children with Sotos syndrome (Lane, Van Herwegen, \& Freeth, 2019), and children with Williams syndrome (WS) (Lane et al., 2019; Laws \& Bishop, 2004; Philofsky et al., 2007). In the present dissertation, I delineate and compare the pragmatic communication abilities of children with WS, a genetic disorder caused by a deletion of $26-28$ genes on chromosome 7q11.23 (Hillier et al., 2003) and its reciprocal syndrome, 7q11.23 duplication syndrome (Dup7), which is caused by an extra copy of the same set of genes (Somerville et al., 2005), and consider the concurrent predictors of pragmatic communication abilities for children with each syndrome. The comparison of reciprocal syndromes allows for consideration of possible effects of gene dosage on the phenotype of each syndrome. In the remainder of this chapter, I provide an overview of the Children's Communication Checklist-2 (CCC-2; Bishop, 2003) - the assessment that will be used to measure language and pragmatic communication in this dissertation, review prior research on factors associated with pragmatic communication ability in typically developing (TD) children and children with disabilities other than WS or Dup7, and then provide a brief overview of WS and Dup7, including prior research on pragmatic abilities. 


\section{Children's Communicative Checklist, Second Edition}

The CCC-2 (Bishop, 2013) assesses the day-to-day communication of children aged $4-16$ years. It is considered the instrument of choice for assessing pragmatic language concerns (Adams, 2001), having a high sensitivity for identifying pragmatic language problems (Bignell \& Cain, 2017; Norbury, Nash, Barid, \& Bishop, 2004; Volden \& Phillips, 2010). The parent report form was used in this dissertation. The CCC2 includes ten scales. The first four measure form and content aspects of language: A. Speech, B. Syntax, C. Semantics, and D. Coherence. (These four scales are referred to as structural language by some authors.) The second four measure pragmatic aspects: E. Initiation, F. Stereotyped Language, G. Use of Context, and H. Nonverbal Communication. The last two scales address social characteristics that often are associated with ASD: I. Social Relations and J. Interests.

An age-standardized scaled score $($ mean $=10, S D=3)$ can be derived from the raw score for each scale. The General Communication Composite (GCC) standard score (SS) is based on the sum of the scaled scores from scales $\mathrm{A}-\mathrm{H}$. The Social Interaction Difference Index (SIDI) is calculated by adding the scaled scores for scales E, H, I, and J (two of the pragmatics scales plus the two ASD-associated scales) and subtracting the sum of scaled scores for scales A through D (the language form and content scales). Scores of -11 or lower are considered consistent with an ASD profile. In contrast, scores of +11 or higher are considered compatible with a specific language impairment (SLI) profile. Scores between -10 and 10 are considered to be in the typical range. 


\section{Factors Associated with Pragmatic Communication as Measured by the CCC-2}

There have been a number of studies looking at the correlates of pragmatic communication ability as measured by the CCC-2 (e.g., Broeders, Geurts, \& JennekensSchinkel, 2010; Leonard, Milich \& Lorch, 2011; Smith, Næss, \& Jarrold, 2017; Timler, 2014). The possible correlates that are most often considered are intellectual ability, language form and content skills, sex, and behavior regulation. Below I briefly summarize the findings regarding relations between pragmatic language ability and each of these variables.

\section{Intellectual Ability}

The findings from studies addressing the relation between intellectual ability and pragmatic language are mixed. There are no studies that have reported the relation between intellectual ability and CCC-2 pragmatic communication for TD children. Lee et al. (2017), using age equivalent scores on the Comprehensive Assessment of Spoken Language (CASL; Carrow-Woolfolk, 1999) Pragmatic Judgment scale found a positive correlation between pragmatic language ability and nonverbal mental age for TD children. Verbal IQ has been found to be positively related to CCC-2 pragmatic communication ability for children with visual impairment (Pijnacker, Vervloed \& Steenbergen, 2012) and children with epilepsy (Broeders et al., 2010). CCC-2 pragmatic communication ability as reported by professionals working with the participants was found to be positively related to both Verbal IQ and Performance (nonverbal) IQ in a clinical sample of children with ASD, ADHD, and/or specific learning disability (Bishop \& Baird, 2001). For children with DS, pragmatic communication ability as measured by the CCC-2 (Udhnani et al., 2019) was positively related to nonverbal IQ. 
In contrast, some studies did not find a significant relation between IQ and CCC-2 pragmatic communication ability. Leonard and colleagues (2011) did not find a significant relation between CCC-2 pragmatic composite and Verbal IQ for children with ADHD. In a clinical sample (including children with ASD, ADHD, or specific learning disability), CCC-2 pragmatic communication ability as reported by parents was not significantly related to Verbal IQ or Performance IQ (Bishop \& Baird, 2001). Udhnani and colleagues (2019) did not find a significant relation between Nonverbal IQ and CCC2 pragmatic communication for children with ASD. Additionally, in contrast to the findings of Lee et al. (2017) and Udhnani et al. (2019), Smith and colleagues (2017) did not find a significant relation between nonverbal ability and pragmatic ability for children with DS. The study by Lee and colleagues (2017) was longitudinal, with three time points and a sample of 22 children. The Smith et al. study (2017) had a sample of 26 children while Udhnani and colleagues (2019) had a sample of 41 children. It is possible the smaller sample with only one time of data collection had insufficient power. In addition, Lee et al. (2017) stated they found the relation differed based on type of assessment and type of pragmatic skill.

\section{Language Form and Content Ability}

Findings from studies addressing the relation between language form and content ability and pragmatic communication ability also are mixed. When language form and content was measured by a composite of the CCC Syntax and Speech scales, Spanoudis, Natsopoulos and Panayiotou (2007) found a positive relation with CCC pragmatic communication ability for both TD children and children with pragmatic language impairment (PLI). Additionally, in a group of children with normal Nonverbal IQ (both 
TD and with ADHD) a positive relation between language form and content ability as measured by the Clinical Evaluation of Language Fundamentals-4 (CEL-4; Semel, Wiig, \& Secord, 2013) and CCC-2 pragmatic communication ability was found (Timler, 2014). Lee et al. (2007) found a positive relation between language form and content ability as measured by the CASL and performance on the CASL Pragmatic Judgment scale for children with DS.

However, other studies did not find a significant relation. Leonard and colleagues (2011) did not find a significant relation between language form and content ability, as measured by the Oral and Written Language Scales (OWLS; Carrowfolk, 1995) Listening Comprehension subtest or the OWLS Oral Expression subtest and CCC-2 pragmatic communication ability in children with ADHD. Spanoudis et al. (2007) did not find a significant relation between CCC structural language ability and CCC pragmatic communication ability for children with SLI. Smith et al. (2017) did not find a significant relation between CCC-2 pragmatic communication ability and either expressive vocabulary ability or receptive vocabulary ability for children with DS, perhaps due to limited power as a result of small sample size.

\section{Behavior and Emotion Regulation}

Behavior regulation encompasses the behaviors (e.g., impulse control) that allow a child to child make socially appropriate behavioral responses. Studies that have addressed the relation of behavior and emotional regulation (typically as measured by level of behavior and emotional problems) to $\mathrm{CCC}-2$ pragmatic communication have found a significant negative relation, that is, higher levels of behavior and emotional problems were associated with lower pragmatic communication ability. Leonard et al. 
(2011) found that for TD children, level of behavior and emotional problems was negatively correlated with CCC-2 pragmatic communication composite. Helland, Lundervold, Heimann, and Posserud (2014) found that for a group of children with externalizing behavior problems at age $7-9$ years, level of externalizing behavior at that age was significantly negatively correlated with CCC-2 Pragmatic Communication ability at $12-15$ years of age. Helland and Helland (2017) found that overall level of behavior and emotional problems was negatively correlated with CCC-2 pragmatic communication ability for both children with SLI and children with ASD who did not have ID. Bignell and Cain (2007) found that children with hyperactivity and/or inattention scored significantly lower on the CCC-2 pragmatic communication composite than children who did not have attention problems. Geurts and Embrechts (2008) found that for 4-7-year-olds with ASD or SLI, higher levels of impulsivity were significantly associated with lower scaled scores on the CCC-2 Initiation, Use of Context, Nonverbal Communication, and Social Relations scales. In contrast, higher levels of inattention or hyperactivity were not significantly related to CCC-2 scaled scores for any scale except Stereotyped Language.

Sex

Sex differences in the performance of TD children on the CCC-2 are frequently found in studies that include large sample sizes. Based on a sample of 1351 children (678 boys, 673 girls) in the Netherlands, Ketelaars et al. (2010) found that girls scored significantly better than boys on each of the CCC scales. Geurts et al. (2009) found that girls $(\mathrm{N}=883)$ scored significantly better than boys $(\mathrm{N}=1,187)$ on seven of the ten CCC scales, although boys scored significantly better that girls on the Speech and Syntax 
scales and there was no significant difference between the performance of boys and girls on the Coherence scale. Each of the reported effect sizes was small. Ash and colleagues (2017) found that girls $(\mathrm{N}=83)$ scored significantly better than boys $(\mathrm{N}=125)$ on a pragmatic composite that included CCC-2 scales $\mathrm{D}-\mathrm{H}$.

In two studies of TD children that included much smaller sample sizes, no significant sex differences were found for CCC-2 scores. Helland et al. (2014) found no significant difference in performance of boys and girls on the CCC-2 GCC composite score, and Laws and Bishop (2001) reported that there were no significant differences between boys and girls on any of the CCC-2 scales. All the CCC-2 studies involving atypical populations have included small sample sizes. In the few cases where sex differences were evaluated statistically, no significant differences were found either between boys and girls with DS (Laws \& Bishop, 2004; Lee et al., 2017) or between boys and girls with SLI (Laws \& Bishop, 2004).

\section{Predictors of Pragmatic Communication}

There has been a limited number of studies that focus on potential predictors of CCC-2 pragmatic communication or on CCC-2 pragmatic communication as a mediator. Leonard et al. (2011), in a community sample of 54 children aged 9 - 11 years, found that pragmatic communication completely mediated the relation between hyperactivity and social skills and partially mediated the relation between inattention and social skills.

Predictors of CCC-2 pragmatic communication ability were considered in three studies conducted by Udhnani and colleagues. In the first study Udhnani et al. (2018) included chronological age (CA), nonverbal IQ, and the Behavior Regulation Index (BRI) and the Metacognitive Index (MCI) from the Behavior Rating Inventory of 
Executive Function (BRIEF; Gioia, Isquith, Guy, \& Kenworthy, 2000) as predictors. Participants were 24 children with sex aneuploidies (14 girls with trisomy X syndrome and 10 boys with Klinefelter syndrome). Only the BRIEF BRI contributed a significant amount of unique variance to individual differences in CCC-2 pragmatic communication composite. In the second study, Udhnani and colleagues (2020) included the BRIEF BRI and $\mathrm{MCI}$ as predictors of CCC-2 pragmatic communication ability for 91 children with ASD. The BRI and the MCI each contributed a significant amount of unique variance to individual differences in CCC-2 pragmatic communication composite. In the third study, Udhnani and colleagues (2020) included the BRIEF-2 (Gioia, Isquith, Guy, \& Kenworthy, 2015) BRI and BRIEF-2 Cognitive Regulation Index (CRI) as predictors of the CCC-2 pragmatic communication abilities of 41 children with DS. Although the overall model accounted for a significant amount of variance in CCC-2 pragmatic communication scores, the BRI only contributed a marginally significant $(p=.06)$ amount of unique variance and the CRI did not contribute significantly to individual differences in CCC-2 pragmatic communication ability.

Lane and colleagues (2019) conducted a regression analysis in a sample of 31 children (17 boys, 14 girls) with Sotos syndrome using Language Form and Content skills (sum of scaled scores for CCC-2 scales A-D), CA, and sex as the predictors. Results indicated that Language Form and Content ability and CA were significant predictors whereas sex was not, with higher Language Form and Content performance and younger CA predicting better pragmatic communication ability. Overall, the predictors accounted for $65 \%$ of the variance in Pragmatic Language Composite. 


\section{Williams Syndrome}

Williams syndrome (WS) is a neurodevelopmental disorder resulting from a hemideletion of 26 - 28 genes on chromosome 7q11.23 (Hillier et al., 2003) and has a prevalence of one in 7,500 live births (Strømme, Bjørnstad, \& Ramstad, 2002). WS is characterized by mild to moderate ID or learning difficulties, dysmorphic facial features, and heart disease (Morris, 2006). Individuals with WS are often described as being gregarious and overly friendly (Gosch \& Pankau, 1997) and highly sociable (Dilts, Morris, \& Leonard, 1990); however, they struggle to make meaningful social connections and have difficulty maintaining friendships (Davies, Udwin, \& Howlin, 1998; Sullivan, Winner, \& Tager-Flusberg, 2003; Tager-Flusberg \& Sullivan, 2000). The combination of having a keen interest in other people and being outgoing and affectionate, yet struggling with social relationships, presents a challenge for many individuals with WS.

\section{Intellectual Ability}

WS is also associated with a cognitive profile characterized by relative strengths in verbal short-term memory, concrete language, phonological processing, and nonverbal reasoning, along with considerable weakness in visuospatial construction (Mervis et al., 2000; Mervis \& Greiner de Magalhães, in press; Mervis \& John, 2010). The Differential Ability Scales-II (DAS-II; Elliott, 2007) can be used to unveil the pattern of relative intellectual strengths and weaknesses masked by a global intelligence score. The mean DAS-II General Conceptual Ability (GCA; similar to IQ) is in the mild ID range, with the full range of ability spanning severe ID to average intellectual ability. Mean Verbal standard score (SS) and mean Nonverbal Reasoning SS are in the borderline intellectual ability range. In contrast, mean Spatial SS is in the mild to moderate ID range. 


\section{Language Form and Content Ability}

Based on their initial study of three adolescents with WS, Bellugi, Marks, Bihrle, and Sabo (1988) argued that individuals with WS had near-normal grammatical abilities, which contrasted strongly with their intellectual abilities, which were described as in the severe ID range. The comparison group in that study was composed of three adolescents with DS matched for CA and IQ. This finding that language was "intact" was due to the contrast of children with WS to children with DS. Currently, it is understood that children with DS have more difficulty than expected with language relative to cognitive ability and not that children with WS have near-normal grammatical ability (Mervis, 1999; Mervis et al., 2004). Udwin, Yule, and Martin (1987) found that for children with WS, grammatical ability was at the same level as that of CA- and IQ-matched children with ID. Grammatical ability is more strongly correlated with verbal working memory for individuals with WS than for TD children (Mervis \& John, 2010). While language is often considered a relative strength for individuals with WS, there is still a specific pattern of relative strength and weakness in vocabulary ability (Mervis \& Greiner de Magalhães, in press). Concrete vocabulary (names for objects, actions, and descriptors) is a relative strength. In contrast, relational vocabulary (labels for spatial, temporal, and quantitative concepts and comparative adjectives) is considerably weaker, with SSs similar to those for spatial ability.

\section{Behavior Regulation}

Across a variety of cultures, parents of children with WS consistently report attention problems as of serious concern (Pérez-García, Brun-Gasca, Pérez-Jurado, \& Mervis, 2017). Almost two-thirds of a sample of 119 children aged $4-16$ years met full 
DSM-IV criteria for Attention Deficit Hyperactivity Disorder (Leyfer et al., 2006).

Additionally, studies utilizing the parent-report BRIEF (Gioia et al., 2000) have identified difficulties in both behavioral regulation (e.g., John \& Mervis, 2010; Pitts, Klein-Tasman, Osborne, \& Mervis, 2016) and metacognition (e.g., John \& Mervis, 2010). Laboratory assessments of behavioral inhibition have also indicated difficulties (Carney, Brown, \& Henry, 2013; Tager-Flusberg, Sullivan, \& Boshart, 1997).

\section{Sex Differences}

Very few studies have compared the performance of boys and girls with WS. Based on parental report but not based on teacher report on the Social Skills Rating Scale (Gresham \& Elliott, 1990), boys $(\mathrm{N}=36)$ had fewer social communication difficulties than girls $(\mathrm{N}=48)($ Klein-Tasman, Li-Barber, \& Magargee, 2011). On the Social Responsiveness Scale (SRS; Constantino \& Gruber 2005) the raw scores of males and females were not significantly different. However, the T-scores for males were significantly lower than for females on all scales based on both parent and teacher report, indicating that relative to same-sex children in the SRS norming sample, males with WS had significantly less difficulty than females on all scales (Klein-Tasman et al., 2011). Laws and Bishop (2004) did not find any significant differences in raw scores between males $(\mathrm{N}=15)$ and females $(\mathrm{N}=4)$ with WS on any of the CCC scales.

\section{Pragmatic Communication}

Although individuals with WS are often characterized as hypersocial, they often also present with social communication (pragmatics) problems (Stojanovik \& James, 2006). The pragmatics abilities of individuals with WS have been assessed using semi- 
structured conversations, standardized assessments, laboratory experiments, and parentreport measures including the $\mathrm{CCC}-2$.

The Autism Diagnostic Observation Schedule (ADOS-2; Lord et al.) has been used in several studies to examine the social-communicative abilities of children with WS. Lincoln et al. (2007) conducted a study with 20 preschoolers with limited or no expressive language and found that they had difficulties in several areas of triadic interaction (e.g., pointing and gesturing, initiating joint attention). In contrast, several areas of dyadic interaction (shared enjoyment, facial expressions, vocalizations, and eye contact) were not problematic. Klein-Tasman et al. (2007), in a study of 29 preschoolers with limited or no expressive language, also identified difficulties in triadic joint attention but not in dyadic joint attention as well as abnormalities in play behavior and repetitive and restricted interests. In that study, almost half the participants met or exceeded criterion for classification as autism spectrum. (Note that classification as autism spectrum on the ADOS does not by itself indicate that the child has ASD; expert clinician judgment - not included as part of this study - that the child has ASD is also needed to make an ASD diagnosis.) Klein-Tasman van der Fluit, and Mervis (2018) completed the ADOS-2 with 40 children with WS aged 3 - 15 years whose language included at least phrase speech but was not fluent and complex. More than half of this sample demonstrated difficulties with relatively complex triadic behaviors such as conversation, directed facial expressions, and showing along with difficulties with sensory interests, repetitive or restrictive behavior, and autism-related mannerisms. However, most participants did not have difficulty with more basic triadic behaviors such as initiation or response to joint attention. The ADOS-2 also was administered to 60 children aged $5-15$ 
years who spoke in fluent, complex sentences. More than half the sample showed abnormalities in complex triadic behaviors such as empathy/comments on others' emotions and insight but did not show abnormalities on less complex triadic behaviors. Across the two groups, $32 \%$ met or exceeded criterion for autism spectrum classification. Across these studies, social communication difficulties were very common. In a separate longitudinal study of language development by children with WS (Becerra \& Mervis, 2019), $19 \%$ of the 47 participants had received a gold standard ASD diagnosis by age 5 years.

Studies using other measures also have identified pragmatic difficulties in preschool children with WS. Using the Pragmatics Profile of Early Communication Skills (Dewart \& Summers, 1995), Stojanovik and James (2006) found that social communication was more delayed than cognitive and motor skills in a case study of a toddler with WS aged 21 months. Findings from another study of toddlers and preschoolers with WS aged $17-55$ months indicated that only one of the toddlers with WS produced referential pointing gestures even in a situation that was designed to elicit this type of gesture (Laing et al., 2002).

The use of play sessions provides another opportunity to observe the use of pragmatic language by older children. John, Dobson, Thomas, and Mervis (2012) considered mother-child play sessions with 14 children with WS at two different ages (Time 1: 4 years; Time 2: $9-12$ years). Results indicated that both the ability to pair eye contact and verbalizations at age 4 years and expressive vocabulary ability at 4 years predicted the ability to add meaningful information to a conversation at age $9-12$ years old. 
John, Rowe, and Mervis (2009), using an experimental task, found that 6 - 12year-olds with WS had difficulty with referential communication. In particular, when the experimenter provided a message that was inadequate for the child to determine the picture to which the experimenter was referring, children indicated that the message was problematic less than half of the time. Consistent with these findings, Stojanovik (2006) reported that 7 - 12-year-olds with WS had difficulty with conversational exchange and turn-taking and that the content of their conversational responses to the researcher tended either to be inadequate or inappropriate.

There have been three studies that used the CCC or CCC-2 to study the language of individuals with WS. Laws and Bishop (2004) compared the CCC performance of 19 individuals with WS aged 6-24 years to similarly-aged individuals with DS, considerably younger children with SLI, and considerably younger TD children. When compared to the individuals with SLI and DS, individuals with WS earned significantly better raw scores on the Syntax scale. Their mean raw score on this scale did not differ significantly from the mean score for the much-younger TD group. The WS group scored considerably worse than the TD group on all the other scales. On the Speech scale, the WS group scored significantly better than the DS group. Individuals with WS earned the worst Pragmatic Composite raw score (based on CCC scales $\mathrm{C}-\mathrm{G}$ ) of all four groups. Approximately $79 \%$ of individuals with WS met the CCC cut-off for pragmatic language impairment. The WS group scored significantly worse than each of the other groups on the Inappropriate Initiation and Stereotyped Conversation scales and significantly worse than the much-younger SLI and TD groups on the Use of Context scale. The difficulty with Inappropriate Initiation identified in this study is consistent with 
the behavioral description of individuals with WS having limited social inhibition (Davies et al. 1998; Klein-Tasman et al., 2010; Udwin, 1990). In addition, Laws and Bishop reported that individuals with WS were rated as being babied, bullied, or teased more often than the other groups of participants.

In the second study, Philofsky and colleagues (2007) compared 21 children with WS $(M$ age $=9.1$ years, $S D=2.2$, range $=6.2-12.5)$ to 22 children with ASD $(M$ age 9.6 years, $S D=1.7$, range $=7.1-12.10$ ). All participants spoke in full sentences. The mean GCC raw score (sum of scaled scores for CCC-2 scales A - H) for the children with WS was $32.3(\mathrm{SD}=12.1$, range $=8-28)$. This score is in the language impairment range. (GCC raw scores of 55 or higher are considered within normal limits, while scores below 55 are considered indicative of some type of language impairment.) The mean pragmatic composite (sum of scaled scores for CCC-2 scales $\mathrm{E}-\mathrm{H}$ ) was $15.8(S D=5)$ with a range from $8-28$, indicating that most of the participants had difficulty with pragmatic communication. (Pragmatic composite scores between 17 and 24 indicate borderline pragmatic language functioning, and scores below 17 indicate impaired pragmatic language functioning.) The SIDI mean was $-6(S D=8$, range $=-17-15)$, which is in the typical range for the standardization sample. (SIDI scores lower than -11 are consistent with an ASD pragmatic profile, scores between -10 and 10 are considered to be in the typical performance range, and scores of +11 or higher are consistent with an SLI profile.) Using raw subscale scores and controlling for expressing language age equivalent, the children with WS performed significantly better than the children with ASD on the Coherence, Stereotyped Language, Nonverbal Communication, and Social 
Relations scales. On the remaining subscales, the two groups did not differ significantly from each other.

Lane et al. (2019) studied 34 children with WS ( $M$ age $=9.4$ years, $S D=3.33$, range $4-16.75)$. CCC-2 GCC raw scores ranged from $4-60(\mathrm{M}=26.82, \mathrm{SD}=10.60)$. Only one participant scored at least 55; the remaining 33 participants scored in the impairment range. The mean sum of scaled scores on the Language Form and Content scales (scales A - D) was $13.97(S D=7.11)$. Mean scaled score for the Speech scale was nominally higher than the mean scaled score for each of the other three structural scales, but no statistical analysis comparing these means was reported. The mean sum of scaled scores for the pragmatic scales (scales $\mathrm{E}-\mathrm{H}$ ) was $12.85(S D=5.85)$. Children with WS scored nominally lower on the Context scale than on the other three pragmatics scales, but no statistical analysis comparing these means was reported. The mean scores for the two Social scales (I - J) did not differ significantly. To identify the predictors of pragmatic language (sum of scaled scores for CCC-2 scales E-H), Lane and colleagues conducted a regression analysis with Language Form and Content skills (sum of scaled scores for CCC-2 scales A-D), CA, and sex as the predictors. Results indicated that Language Form and Content ability and CA were significant predictors whereas sex was not, with higher Language Form and Content performance and lower CA predicting better pragmatic communication ability. Note that the negative relation between CA and pragmatic communication ability obtained even though scaled scores (which are ageadjusted) were used to measure pragmatic ability, indicating that older children with WS perform worse than younger children with WS relative to same-aged children in the 
standardization sample. Overall, the predictors accounted for $25 \%$ of the variance in Pragmatic Language Composite.

\section{7q11.23 Duplication Syndrome (Dup7)}

Dup7 is a genetic disorder resulting from an extra copy of the same set of genes as is deleted in WS (Somerville et al., 2005). The estimated prevalence of Dup7 is 1 in 7,500 births (Velleman \& Mervis, 2011). Dup7 is characterized by developmental delay, ASD, speech and language delay/disorder, social anxiety disorder and selective mutism, dysmorphic facial features, macrocephaly, hypotonia, and decreased pain sensitivity (Mervis et al., 2015; Morris et al., 2015). The first case of Dup7 was identified in late 2004 and reported in 2005 (Somerville et al., 2005). Due to the recent recognition of this syndrome, there are very few studies of individuals with Dup7.

\section{Intellectual Ability}

On average, individuals with Dup7 demonstrate low average overall intellectual ability, with a range from severe ID to high average ability (Mervis et al., 2015). The cognitive profile of children with Dup7 is variable, but the most common profile is flat, with no significant differences in DAS-II Verbal, Nonverbal Reasoning, and Spatial SSs. On the Mullen Scales of Early Learning (MSEL; Mullen, 1995) toddlers and young preschoolers with Dup7 earned significantly lower T-scores on the Expressive Language scale than on the Receptive Language or Visual Reception (nonverbal reasoning) scales (Mervis et al., 2015).

\section{Language Form and Content Ability}

Speech problems and language delay are hallmarks of Dup7 (Morris et al., 2015; Somerville et al., 2005). Speech articulation ability is considerably worse than expected 
for overall intellectual ability (Huffman, 2019). Mean SS for receptive vocabulary ability as measured by the Peabody Picture Vocabulary Test-4 (PPVT-4; Dunn \& Dunn, 2007) was in the average range, with mean SS for the Expressive Vocabulary Test-2 (EVT-2; Williams, 2007) in the low average range (Mervis et al., 2015). For both measures, performance spanned the severe disability to high average range. Grammatical development is considerably more delayed than vocabulary development (Velleman \& Mervis, 2011).

\section{Behavior and Emotion Regulation}

Individuals with Dup7 present as shyer and more socially inhibited than children with WS (Velleman \& Mervis, 2011). Approximately three-fourths of individuals with Dup7 have at least one anxiety disorder diagnosis (Mervis et al., 2015), with the most prevalent disorders being specific phobia, social phobia, and selective mutism. Avoidance of interaction with new people is likely secondary to anxiety and language problems (Velleman \& Mervis, 2011). Approximately one-third of children with Dup7 met full DSM-IV criteria for ADHD and approximately one fourth met full DSM-IV criteria for oppositional defiant disorder or disruptive behavior disorder - not otherwise specified (Mervis et al., 2015).

\section{Sex Differences}

None of the studies of children with Dup7 has assessed whether sex differences are present.

\section{Pragmatic Communication Ability}

The only study that has addressed pragmatic ability in children with Dup7 is Klein-Tasman and Mervis (2018), who used the ADOS-2 to investigate the social- 
communicative skills of $634-17$-year-olds with Dup7 (mean CA: 8.81 years, $S D=$ 3.91). Most of the 21 children who used phrase speech or simple sentences did not demonstrate difficulty with unusual eye contact, pointing, requesting, or initiating or responding to joint attention. In contrast, more than half of them demonstrated problems with overall level of language, speech abnormalities associated with autism, conversation, more advanced gestures, overall quality of rapport, imagination/creativity, and anxiety. Most of the 33 children who used fluent, complex language did not demonstrate difficulty with overall level of language, offering information, coordinating language with nonverbal communication, shared enjoyment, or social overtures. In contrast, more than half of them demonstrated difficulties with asking for information, empathy, insight, and overall quality of rapport. Across all ADOS-2 modules, overall rapport was a difficulty for approximately half of the sample. Klein-Tasman and Mervis (2018) did include expert clinical judgment in this study in addition to administering the ADOS-2, allowing for gold-standard DSM-IV diagnosis of ASD. Nineteen percent of the participants were diagnosed with ASD. Elevated rates of ASD based on less rigorous procedures also have been reported in other studies (Earhart et al., 2017; van der Aa et al., 2009). In socially comfortable settings, individuals with Dup7 often show appropriate pragmatic skills (Velleman \& Mervis, 2011). There have been no publications reporting the performance of children with Dup7 on the CCC-2.

\section{Present Dissertation}

Appraising the language of children with WS and Dup7 will help in understanding communication difficulties encountered by children with these syndromes. Three research questions were addressed in this dissertation. The first research question was, 
what is the overall level of language and communication ability as measured by the CCC2 for each syndrome, relative to CA expectations? The second research question was, what is the pattern of relative strengths and weaknesses in language form and content, pragmatic communication, and ASD-related behaviors for each syndrome? The final question was, what are the concurrent predictors of pragmatic communication ability for each syndrome? The answers to these questions will allow for a preliminary consideration of the impact of gene dosage of one or more of the genes in the WS region on language and communication ability.

In the next chapter, the methods for the dissertation are presented. In Chapter III, I present the findings from the parental-report of their child's language abilities as measured by the CCC-2, allowing for a description of children's language and communication abilities, including relative strengths and weaknesses. Performance on a variety of potential concurrent predictors of pragmatic communication ability, including parental report of behavioral regulation and emotional regulation and direct assessment of nonverbal reasoning ability, also are reported. Finally, separate linear multiple regressions addressing concurrent predictors of pragmatic communication ability for children with WS and children with Dup7 are presented. Chapter IV provides an overall discussion of the findings. 


\section{CHAPTER II}

\section{METHOD}

As stated in the previous chapter, the current dissertation had three main goals. The first goal was to examine the overall level of language and communication ability as measured by the CCC-2 for children with WS and children with Dup7 relative to CA expectations. The second research goal was to determine the pattern of relative strengths and weaknesses in language form and content, pragmatic communication, and ASDrelated behaviors for both children with WS and children with Dup7. The final goal was to identify the concurrent predictors of pragmatic communication ability for children with each of the two syndromes.

\section{Participants with Williams Syndrome}

All participants with WS were recruited for a larger study of language, cognitive, and behavioral development conducted at the University of Louisville. Between October 2004 and June 2019, 252 children with classic WS (deletion of the 26 - 28 genes in the Williams syndrome region on chromosome 7q11.23) aged $6.00-15.50$ years completed the assessment protocol used in the dissertation. Four of these children (two females, two males; ages $6.38-9.29$ years) were excluded because they did not reliably produce spontaneous word combinations, so they did not meet the minimum language requirement for the $\mathrm{CCC}-2$. One additional male was excluded because he also had fetal alcohol syndrome. The final WS sample for this dissertation was composed of the remaining 247 children (126 females, 121 males), who ranged in age from $6.01-15.50$ 
years $(M=10.57$ years, $S D=2.96, M d n=10.28)$. Many of the children were participating in a longitudinal study and therefore completed the assessment protocol more than once (with at least 12 months between assessments). For these children, the most recent set of data within the $6.00-15.50$-year age range was used. For the 203 participants (82.19\% of the full sample) who also completed the DAS-II (Elliott, 2007) as part of their larger assessment, mean GCA (similar to IQ) was 63.23 ( $S D=13.49$, range: 28 -96). The GCAs of the four children who were excluded because they were not reliably producing spontaneous word combinations ranged from $30-35$.

At the time of their assessment, English was the primary language of all participants. However, one child (who was adopted internationally as a toddler) was initially exposed only to a different language, and 11 children had been exposed to another language (either solely or in addition to English) at home beginning from birth. The racial-ethnic breakdown of the sample was: $81.8 \%$ White non-Hispanic, $6.9 \%$ White Hispanic, 1.2\% African-American non-Hispanic, 2.4\% Asian non-Hispanic, 6.1\% multiracial non-Hispanic, and 1.6\% multiracial Hispanic. The sample included children living in 38 U. S. states, 2 Canadian provinces, and the United Kingdom. All four U. S. census regions were represented: Northeast (19.0\%), South (36.4\%), Midwest (28.9\%), and West (14.6\%), as well as Canada and the United Kingdom (2.0\%).

\section{Participants with 7q11.23 Duplication Syndrome}

The assessment protocol used in this dissertation was administered to 59 children with genetically-confirmed classic Dup7 (duplication of the 26-28 genes that are deleted in classic WS) aged $6.08-15.29$ years. These children were assessed between January 2005 and October 2016. Three of them (one female, two males; ages 6.04-8.84 
years) were excluded because they did not reliably produce spontaneous word combinations so did not meet the minimum language requirement for the CCC-2. The final Dup7 sample for this dissertation was composed of the remaining 56 children (28 females, 28 males), who ranged in age from $6.08-15.29$ years $(M=10.33$ years, $S D=$ $2.82, M d n=10.20$ ). For the few participants who were followed longitudinally and therefore completed the assessment protocol more than once (with at least 12 months between assessments), the most recent set of data within the $6.00-15.50$-year age range was used. All 56 participants completed the DAS-II (Elliott, 2007) as part of their assessment. Mean GCA was 83.43 ( $S D=16.17$, range: $39-132)$. The GCAs of the three children who were excluded because they were not reliably producing word combinations ranged from $39-42$.

At the time of their assessment, English was the primary language of all participants. However, English was the second language to which one child was exposed. The racial-ethnic breakdown of the sample was: $76.8 \%$ White non-Hispanic, 3.6\% White Hispanic, 5.4\% African-American non-Hispanic, 3.6\% Asian non-Hispanic, 7.1\% multiracial non-Hispanic, and 3.6\% multiracial Hispanic. The sample included children living in 23 U. S. states, 1 Canadian province, and the United Kingdom. All four U. S. census regions were represented: Northeast (16.1\%), South (32.1\%), Midwest (30.4\%), West (17.9\%), as well as Canada and the United Kingdom (3.6\%).

\section{Measures}

Children's Communication Checklist-2 United States edition (Bishop, 2006).

The CCC-2 is a 70-item questionnaire designed to assess children's communication skills. The CCC-2 is normed for children aged 4.00 to 16.99 years who produce spontaneous 
word combinations. As indicated in Chapter I, the CCC-2 is often used to measure the communicative abilities of children with developmental disabilities. The American version of the CCC-2 is designed for children whose primary language is English. The rater is asked to indicate the frequency the behavior described in an item is observed in the child, using the following scale: 0 (less than once a week or never), 1 (at least once a week but not every day, or occasionally), 2 (once or twice daily, or frequently), 3 (several times a day - more than twice; or always).

The CCC-2 includes 10 scales. The first four measure language form and content: A. Speech, B. Syntax, C. Semantics, and D. Coherence, The second four measure pragmatic aspects of communication: E. Initiation, F. Stereotyped Language, G. Use of Context, and H. Nonverbal Communication. The last two scales address social characteristics that often are associated with ASD: I. Social Relations and J. Interests. Each scale includes seven items: five that address difficulties a child may have and two that address possible strengths. For scoring purposes, items measuring possible strengths are reverse-coded, so that lower raw scores indicate better performance for all items included in the CCC-2. Examples of the items on each scale are provided in Table 1. 


\section{Table 1}

Examples of CCC-2 Items Measuring Communication Difficulty or Strength as a Function of CCC-2 Scale

\begin{tabular}{|c|c|c|}
\hline Scale & Item Focused on Difficulty & Item Focused on Strength \\
\hline Speech & $\begin{array}{l}\text { Simplifies words by leaving out some } \\
\text { sounds. }\end{array}$ & $\begin{array}{l}\text { Speaks fluently and clearly, producing } \\
\text { all speech sounds and without any } \\
\text { hesitation. }\end{array}$ \\
\hline Syntax & Leaves out "is." & $\begin{array}{l}\text { Produces sentences containing } \\
\text { "because" such as "John got a cake } \\
\text { because it was his birthday." }\end{array}$ \\
\hline Semantics & $\begin{array}{l}\text { Is vague in a choice of words, making } \\
\text { it unclear what s/he is talking about, } \\
\text { e.g., saying "that thing" rather than } \\
\text { "pan." }\end{array}$ & $\begin{array}{l}\text { Uses abstract words that refer to } \\
\text { general concepts rather than something } \\
\text { you can see, e.g., knowledge, politics, } \\
\text { courage. }\end{array}$ \\
\hline Coherence & $\begin{array}{l}\text { Confuses a sequence of events when } \\
\text { trying to tell a story or describe a } \\
\text { recent event. }\end{array}$ & $\begin{array}{l}\text { Talks clearly about what s/he plans to } \\
\text { do in the future (e.g., what s/he will do } \\
\text { tomorrow or plans for going on } \\
\text { vacation) }\end{array}$ \\
\hline Initiation & $\begin{array}{l}\text { Talks to people without any } \\
\text { encouragement or starts conversations } \\
\text { with strangers. }\end{array}$ & Talks to others about their interests. \\
\hline $\begin{array}{l}\text { Stereotyped } \\
\text { Language }\end{array}$ & Repeats phrases said by an adult. & $\begin{array}{l}\text { You can have enjoyable, interesting } \\
\text { conversations with him or her. }\end{array}$ \\
\hline Context & $\begin{array}{l}\text { Talks easily with one familiar adult, } \\
\text { but has difficulty expressing } \\
\text { himself/herself in a group of children. }\end{array}$ & $\begin{array}{l}\text { Appreciates the humor expressed by } \\
\text { irony, e.g., would be amused rather } \\
\text { than confused if someone said, "Isn't it } \\
\text { a nice day" when it was raining. }\end{array}$ \\
\hline $\begin{array}{l}\text { Nonverbal } \\
\text { Communication }\end{array}$ & $\begin{array}{l}\text { Looks blank in a situation where most } \\
\text { children would show a clear facial } \\
\text { expression. }\end{array}$ & $\begin{array}{l}\text { Smiles appropriately when talking } \\
\text { with people. }\end{array}$ \\
\hline Social Relations & $\begin{array}{l}\text { Is babied, teased or bullied by other } \\
\text { children. }\end{array}$ & $\begin{array}{l}\text { Shows concern when other people are } \\
\text { upset. }\end{array}$ \\
\hline Interests & $\begin{array}{l}\text { Moves the conversation to a favorite } \\
\text { topic, even if others are not interested } \\
\text { in it. }\end{array}$ & $\begin{array}{l}\text { Reacts positively when a new and } \\
\text { unfamiliar activity is suggested. }\end{array}$ \\
\hline
\end{tabular}

An age-standardized scaled score $(M=10, S D=3)$ can be derived from the raw score for each scale. The General Communication Composite (GCC) is the sum of the scaled scores for scales A $-\mathrm{H}$. The GCC SS is derived from this sum. To determine if a 
child demonstrates ASD-type communication problems or SLI-type language form and content problems, a Social Interaction Difference Index (SIDI) may be calculated by adding the scaled scores for scales E, H, I, J and subtracting the sum of scaled scores for scales A through D. Scores of -11 or lower are considered consistent with an ASD profile, scores from $-10-10$ are considered typical, and scores of +11 or higher are considered consistent with an SLI profile.

The United States version was normed on 950 children aged 4.00 - 16.99 years. According to the CCC-2 U. S. edition manual (Bishop, 2006), for the full U. S. norming sample, mean internal consistency for the GCC was .95 , with a range from .94 to .96 for the age bands included in the dissertation. For the full U. S. norming sample, average internal consistency for the 10 scales ranged from .65 for J. Interests to .78 for A. Speech and G. Context. For the age range in the present dissertation, internal consistency ranged from .61 for 6-year-olds for J. Interests to .85 for E. Initiation and G. Context for 10- and 11-year olds.

\section{Behavior Rating Inventory of Executive Functioning-2, parent form (BRIEF-}

2; Gioia et al., 2015). The BRIEF-2 is a measure of executive function ability normed for children aged $5-18$ years. The BRIEF-2 parent-report form contains 63 items within nine clinical scales: Inhibit, Self-Monitor, Shift, Emotional Control, Initiate, Working Memory, Plan/Organize, Task Monitor, and Organization of Materials. The nine scales are combined into three Indexes: Behavior Regulation Index (BRI), Emotion Regulation Index (ERI), and Cognitive Regulation Index (CRI). The BRI and the ERI were used in this dissertation. The BRI represents the child's ability to regulate and monitor behavior effectively. It is composed of the Inhibit and Self-Monitor scales. The ERI represents the 
child's ability to regulate emotional responses and to adjust to changes in the environment, people, plans, or demands. It is composed of the Shift and Emotional Control scales. Performance on the Indexes is measured by T scores, with a mean of 50 and a SD of 10. Higher scores indicate greater difficulty. The BRIEF-2 was normed on 1400 children ( 687 males, 713 females) aged $5-18$ years. The Parent Form test-retest reliability is .83 for the BRI and .82 for the ERI (Gioia et al., 2015). For the participants in this dissertation, the correlation between BRIEF BRI and BRIEF ERI was .65 for the WS group and .50 for the Dup7 group. To reduce the number of independent variables used in the regression analyses, a composite Behavioral and Emotional Functioning Tscore was computed by averaging the child's BRI and ERI T-scores.

Participants' parents completed the first edition of the BRIEF (Gioia et al., 2000). All of the items on the BRIEF-2 that are included in the computation of T-scores are also included in the first edition of the BRIEF, allowing BRIEF-2 T-scores to be computed from administrations of the BRIEF. Following the test authors' recommendation (L. Kenworthy, personal communication to Carolyn Mervis, October 7, 2020), raw scores from the relevant items on the BRIEF were used to compute BRIEF-2 T-scores.

\section{Kaufman Brief Intelligence Test-2 (KBIT-2; Kaufman \& Kaufman, 2004).}

The KBIT-2 assesses verbal and nonverbal intelligence independently, providing a Verbal SS, Nonverbal SS, and an IQ Composite. For this dissertation, only the nonverbal scale was used. This scale measures matrix reasoning, so it is a measure of nonverbal reasoning rather than overall nonverbal ability. The KBIT-2 is normed for individuals aged $4-90$

years old. For the general population, the mean SS is $100(S D=15)$, with a range from 40 
- 160. The Nonverbal SS demonstrated high internal consistency $(\alpha=.86)$ for the norming sample.

\section{Procedure}

The protocol used for this study was reviewed and approved by the University of Louisville Institutional Review Board. Parents signed an informed consent form and all children provided either oral or written assent. The CCC-2 and BRIEF were mailed to the parents prior to the scheduled assessment date. The mother was asked to fill these forms out in advance and bring them with her to the assessment. Both questionnaires were scored according to the standardized procedures. The KBIT-2 was administered to the child by a trained examiner according to the standardized procedures and was scored according to the standardized procedures.

\section{Analyses}

All analyses were completed in SPSS version 26. Data met all assumptions for the analyses used.

To compare the performance of children with WS and children with Dup7 on the CCC-2 scales, three mixed ANOVAs were conducted using the scaled scores for the Language Form and Content Scales, Pragmatic Communication Scales, and Autismrelated Scales respectively as the within-subject factor and Syndrome and Sex as the between-subject factors. For comparisons that included more than two CCC-2 scales, if the main effect of CCC-2 Scale was significant, the Sidak adjustment for multiple comparisons was used to compare scaled scores on each pair of scales. When significant main effects were tempered by significant interactions, the interactions were interpreted rather than the main effects. If the interaction of CCC-2 Scale and either Syndrome or 
Sex was significant, it was followed up first with two repeated measures ANOVAs with CCC-2 Scale as the dependent variable, one for each Syndrome (if the Scale X Syndrome interaction was significant) or one for each Sex (if the Scale X Sex interaction was significant). If the effect of the CCC-2 scale was significant, the Sidak adjustment was used to identify significant differences in scaled scores between pairs of scales. Second, the significant interaction was followed up by two sets of independent sample $t$-tests for each of the CCC-2 scales, one set for each Syndrome or each Sex. The Bonferroni correction for multiple comparisons was used to identify significant differences in scaled scores on a particular CCC-2 scale as a function of Syndrome or Sex, with $\alpha=.0125$ (.05/4), 2-tailed for comparisons for the Language Form and Content or Pragmatic Communication scales and $\alpha=.025$ (.05/2), 2-tailed for comparisons for the Autismrelated scales. For the comparisons involving GCC SS or SIDI as the dependent variable, two-way ANOVAs were conducted with Syndrome and Sex as the between-subject factors. Cohen's $d$ was used to measure effect size $(.20=$ small effect, $.50=$ medium effect, $.80=$ large effect).

Due to the large difference in sample size between the WS group and the Dup7 group, it was important to confirm that it was appropriate to conduct ANOVAs that included both syndromes and both sexes. To confirm that there were no significant differences in variance between the two syndromes for any of the dependent variables to be included in any of the ANOVAs, Levene's test for equality of variances was calculated for each dependent variable. None of the test statistics was significant; $p$ values ranged from $.117-.910$. To confirm that the distribution of males and females 
was similar for the two syndromes, a $\chi^{2}$ test was conducted. The test statistic was not significant, $\chi^{2}(1,303)=0.019, p=.891$. 


\section{CHAPTER III}

\section{RESULTS}

As stated in the previous chapters, the current dissertation had three main goals. The first goal was to examine the overall level of language and communication ability as measured by the CCC-2 for children with WS and children with Dup7 relative to CA expectations. The second goal was to determine the pattern of relative strengths and weaknesses in language form and content, pragmatic communication, and ASD-related behaviors for both children with WS and children with Dup7. The final goal was to identify the concurrent predictors of pragmatic communication ability for children with each of the two syndromes.

\section{CCC-2: Descriptive Statistics and Correlations among Scaled Scores}

Descriptive statistics for performance on the CCC-2 are shown in Table 2, separately for each syndrome. As is clear from the table, there was considerable withinsyndrome variability in performance on each of the CCC-2 measures. 
Table 2

Descriptive Statistics for Parents' Ratings of the Performance of Children with Williams

Syndrome and 7q11.23 Duplication Syndrome on the Children's Communication Checklist-2

\begin{tabular}{|c|c|c|c|c|c|c|c|c|}
\hline \multirow[b]{2}{*}{ Scale or Composite } & \multicolumn{4}{|c|}{ WS } & \multicolumn{4}{|c|}{ Dup7 } \\
\hline & Mean & Median & SD & Range & Mean & Median & SD & Range \\
\hline \multicolumn{9}{|l|}{ Form and Content } \\
\hline Speech & 7.11 & 7.00 & 3.19 & $1^{\mathrm{a}}-13$ & 4.32 & 3.50 & 3.00 & $1^{a}-12$ \\
\hline Syntax & 6.82 & 7.00 & 3.39 & $1^{a}-12$ & 6.20 & 6.50 & 3.69 & $1^{a}-12$ \\
\hline Semantics & 6.42 & 7.00 & 2.47 & $1^{a}-13$ & 6.38 & 6.00 & 2.96 & $1^{a}-13$ \\
\hline Coherence & 5.60 & 5.00 & 2.49 & $1^{a}-13$ & 5.57 & 5.00 & 2.55 & $1^{a}-13$ \\
\hline Mean & 6.49 & 6.50 & 2.33 & $1^{\mathrm{a}}-12.5$ & 5.62 & 5.63 & 2.46 & $1^{\mathrm{a}}-10.25$ \\
\hline
\end{tabular}

Pragmatic

Communication

$\begin{array}{lcccccccc}\text { Initiation } & 5.33 & 5.00 & 2.57 & 1^{\mathrm{a}}-15 & 6.18 & 6.00 & 2.45 & 1^{\mathrm{a}}-12 \\ \text { Scripted Language } & 7.20 & 8.00 & 2.44 & 1^{\mathrm{a}}-14 & 6.59 & 6.50 & 2.47 & 2-14 \\ \text { Context } & 5.40 & 5.00 & 2.36 & 1^{\mathrm{a}}-13 & 5.18 & 5.50 & 3.38 & 1^{\mathrm{a}}-10 \\ \text { Nonverbal Comm. } & 6.74 & 7.00 & 2.41 & 2-14 & 4.96 & 4.00 & 2.80 & 1^{\mathrm{a}}-12 \\ \text { Mean } & 6.17 & 6.25 & 1.99 & 1^{\mathrm{a}}-13.50 & 5.73 & 5.63 & 2.00 & 1^{\mathrm{a}}-10.25\end{array}$

ASD-related

$\begin{array}{lllllllll}\text { Social Relations } & 7.75 & 8.00 & 2.44 & 3-13 & 5.16 & 5.00 & 2.63 & 1^{\mathrm{a}}-13 \\ \text { Interests } & 6.82 & 6.00 & 2.86 & 1^{\mathrm{a}}-16 & 7.48 & 7.00 & 2.69 & 2-13\end{array}$

Overall

$\begin{array}{lllllllll}\text { GCC } & 50.64 & 50.00 & 16.01 & 12-104 & 45.98 & 44.00 & 15.95 & 13-82 \\ \text { CCC-2 Comp. SS } & 77.38 & 77.00 & 12.33 & 44-124 & 73.18 & 73.00 & 12.36 & 45-102 \\ \text { SIDI } & 0.69 & 1.00 & 8.12 & -21-22 & 1.30 & 2.50 & 9.45 & -22-22\end{array}$

Note $:$ Scripted $=$ Scripted Language Context = Use of Context Comm. = Communication; Comp. = Composite; $\mathrm{SS}=$ Standard Score; $\mathrm{ScS}=$ Scaled Score GCC = General Communication Composite; SIDI = Social Interaction Difference Index; WS = Williams syndrome; Dup7 = 7q11.23 duplication syndrome 
To determine relations between scaled scores on each of the 10 CCC-2 scales, Pearson correlations were computed. Correlations are reported in Table 3 for children with WS and Table 4 for children with Dup7. For these analyses, $\alpha$ was set at .01. As can be seen in Table 3, all correlations between pairs of scaled scores were significant for children with WS. For children with Dup7, most of the correlations were statistically significant. For those that were not, the lack of statistical significance was most likely due to limited power for all of the remaining correlations except for the correlations of Speech and Syntax with Nonverbal Communication and Interests. That is, the magnitude of all of the other correlations that were not statistically significant was similar or larger than the magnitude of the smallest significant correlations for the WS sample. A correlation also was computed for each syndrome between the mean scaled score for the Language Form and Content scales and the mean scaled score for the Pragmatic Communication scales. This correlation was $r=.72(p<.001)$ for the WS group and $r$ $=.59(p<.001)$ for the Dup7 group. To determine if the high correlations between the mean scaled score for the Language Form and Content scales and the mean scaled score for the Pragmatic Communication scales for the two groups were due to the relations of each of these measures to overall intellectual ability, partial correlations controlling for DAS-II GCA were computed. These correlations were $r=.63(p<.001)$ for the WS group and $r=.50(p<.001)$ for the Dup7 group, indicating that the highly significant relations between language form and content ability and pragmatic communication found for both syndromes could not be attributed primarily to shared relations with overall intellectual ability. 
Table 3

Correlations between Scaled Scores on the CCC-2 Scales for Children with Williams Syndrome

\begin{tabular}{|c|c|c|c|c|c|c|c|c|c|}
\hline Scale & A. & B. & $\mathrm{C}$. & D. & E. & F. & G. & $\mathrm{H}$. & I. \\
\hline \multicolumn{10}{|l|}{ A. Speech } \\
\hline B. Syntax & $.65^{* *}$ & & & & & & & & \\
\hline C. Semantics & $.50^{* *}$ & $.46^{* *}$ & & & & & & & \\
\hline D. Coherence & $.45^{* *}$ & $.49^{* *}$ & $.65^{* *}$ & & & & & & \\
\hline E. Initiation & $.43^{* *}$ & $.44^{* *}$ & $.39^{* *}$ & $.45^{* *}$ & & & & & \\
\hline F. Scripted Language & $.43^{* *}$ & $.46^{* *}$ & $.51^{* *}$ & $.60^{* *}$ & $.47^{* *}$ & & & & \\
\hline G. Context & $.45^{* *}$ & $.50^{* *}$ & $.57^{* *}$ & $.62^{* *}$ & $.57^{* *}$ & $.61^{* *}$ & & & \\
\hline H. Nonverbal Comm. & $.42^{* *}$ & $.52^{* *}$ & $.36^{* *}$ & $.48^{* *}$ & $.53^{* *}$ & $.55^{* *}$ & $.55^{* *}$ & & \\
\hline I. Social Relations & $.27^{* *}$ & $.27^{* *}$ & $.31^{* *}$ & $.35^{* *}$ & $.38^{* *}$ & $.48^{* *}$ & $.48^{* *}$ & $.49^{* *}$ & \\
\hline J. Interests & $.31^{* *}$ & $.33^{* *}$ & $.30^{* *}$ & $.38^{* *}$ & $.66^{* *}$ & $.52^{* *}$ & $.50^{* *}$ & $.48^{* *}$ & $.54^{* *}$ \\
\hline
\end{tabular}

Note. Comm $=$ Communication

${ }^{* *} p \leq .001$ 
Table 4

Correlations between Scaled Scores on the CCC-2 Scales for Children with Duplication 7q11.23 Syndrome

\begin{tabular}{lccccccccc}
\hline \multicolumn{1}{c}{ Scale } & A. & B. & C & D. & E. & F. & G. & H. & I. \\
\hline A. Speech & & & & & & & & \\
B. Syntax & $.60^{* *}$ & & & & & & & \\
C. Semantics & $.41^{*}$ & $.53^{* *}$ & & & & & & \\
D. Coherence & $.45^{* *}$ & $.52^{* *}$ & $.68^{* *}$ & & & & & & \\
E. Initiation & .29 & .24 & $.35^{*}$ & $.46^{* *}$ & & & & \\
F. Scripted Language & .28 & $.34^{*}$ & $.49^{* *}$ & $.54^{* *}$ & $.45^{* *}$ & & & & \\
G. Context & $.35^{*}$ & $.44^{* *}$ & $.50^{* *}$ & $.72^{* *}$ & $.41^{*}$ & $.59^{* *}$ & & & \\
H. Nonverbal Comm. & .19 & .17 & $.40^{* *}$ & $.54^{* *}$ & $.50^{* *}$ & $.51^{* *}$ & $.55^{* *}$ & & \\
I. Social Relations & .31 & .31 & $.54^{* *}$ & $.57^{* *}$ & $.48^{* *}$ & $.50^{* *}$ & $.57^{* *}$ & $.59^{* *}$ & \\
J. Interests & .16 & .09 & .33 & $.38^{*}$ & $.61^{* *}$ & $.55^{* *}$ & $.52^{* *}$ & $.56^{* *}$ & $.60^{* *}$
\end{tabular}

Note. Comm $=$ Communication

${ }^{*} p \leq .01,{ }^{* *} p \leq .001$

\section{Research Question 1: Overall Language Performance}

The first research goal was to examine the overall level of language and communication ability as measured by the CCC-2 for children with WS and children with Dup7 relative to CA expectations. To address this research question, a two-way ANOVA was conducted with CCC-2 Composite SS as the dependent variable and Syndrome and Sex as the between-subject factors. Descriptive statistics for the CCC-2 Composite SS and the SIDI are provided in Table 5, separately for each syndrome (first for all individuals with that syndrome and then separately for girls and boys) and then for the entire sample and for girls and boys within the entire sample. The main effect of Syndrome was significant, $F(1,299)=5.29, p=.022 . \eta^{2}=.02$. The CCC-2 Composite SS was significantly higher for children with WS than children with Dup7, $d=.33$. 
Neither the main effect of Sex, $F(1,299)=3.55, p=.061, \eta^{2}=.01$, nor the Sex X

Syndrome interaction, $F(1,299)=.81, p=.368, \eta^{2}=.02$ was statistically significant. The significant effect of Syndrome, with the WS group's mean GCC SS significantly higher than the Dup7 group's mean GCC SS, is particularly noteworthy given that mean DAS-II GCA was significantly higher for the Dup7 group $(M=83.43, S D=16.17)$ than the WS group $(M=63.23, S D=13.49), t(257)=9.49, p<.001, d=1.36$, with a very large effect size. In addition the mean DAS-II Verbal SS was significantly higher for the Dup7 group $(M=85.25, S D=16.77)$ than the WS group $(M=71.91, S D=17.79), t(257)=5.03, p$ $<.001, d=.77$. 
Table 5

Descriptive Statistics for the CCC-2 Composite Standard Score and the Social Interaction Difference Index for Children with Williams Syndrome or 7q11.23 Duplication Syndrome

\begin{tabular}{|c|c|c|c|c|c|c|c|c|}
\hline & \multirow[b]{2}{*}{ Sample } & \multirow[b]{2}{*}{$\mathrm{N}$} & \multicolumn{3}{|c|}{ Composite SS } & \multicolumn{3}{|c|}{ SIDI } \\
\hline & & & Mean & SD & Range & Mean & SD & Range \\
\hline \multicolumn{9}{|l|}{ WS } \\
\hline & Full Sample & 247 & 77.38 & 12.33 & $-44-24$ & 0.69 & 8.12 & $-21-22$ \\
\hline & Girls & 126 & 78.26 & 12.70 & $44-113$ & 2.54 & 7.47 & $-20-22$ \\
\hline & Boys & 121 & 76.47 & 11.92 & $-20-22$ & -1.24 & 8.34 & $-21-19$ \\
\hline \multicolumn{9}{|l|}{ Dup7 } \\
\hline & Full Sample & 56 & 73.18 & 12.36 & $45-102$ & 1.30 & 9.45 & $-22-22$ \\
\hline & Girls & 28 & 75.71 & 11.97 & $52-102$ & 1.75 & 9.92 & $-18-22$ \\
\hline & Boys & 28 & 70.64 & 12.43 & $45-93$ & .86 & 9.13 & $-22-15$ \\
\hline \multicolumn{9}{|l|}{ Total } \\
\hline & Full Sample & 303 & 76.61 & 12.43 & $44-124$ & 0.80 & 8.37 & $-22-22$ \\
\hline & Girls & 154 & 77.80 & 12.57 & $44-113$ & 2.40 & 7.94 & $-20-22$ \\
\hline & Boys & 149 & 75.38 & 12.57 & $44-113$ & -0.85 & 8.50 & $-22-19$ \\
\hline
\end{tabular}

To further address the first research question, a two-way ANOVA was conducted with CCC-2 SIDI as the dependent variable and Syndrome and Sex as the betweensubject factors. Neither the main effect of Syndrome, $F(1,299)=0.29, p=.592, \eta^{2}=.00$ nor the main effect of Sex, $F(1,299)=3.68, p=.056, \eta^{2}=.01$ was statistically 
significant. The Sex X Syndrome interaction also was not statistically significant, $F(1$, 299) $=1.41, p=.237, \eta^{2}=.01$.

The final analysis for Research Question 1 involved determination of the proportion of children with each syndrome who met the CCC-2 criterion for language impairment (CCC-2 Composite SS $<80$, corresponding to GCC $<55$ ). Based on this criterion, $71.4 \%$ of the children with Dup7 and $60.3 \%$ of the children with WS had a language impairment. A $\chi^{2}$ test was conducted to determine if there was a significant difference in proportion of children with language impairment in the two groups. The difference was not statistically significant, $\chi^{2}(1,303)=2.40, p=.121$.

\section{Research Question 2: Patterns of Relative Strengths}

The second research goal was to determine the pattern of relative strengths and weaknesses in language form and content, pragmatic communication, and ASD-related behaviors for children with WS and children with Dup7 and to compare these patterns. Findings for each of the three CCC-2 components are reported separately.

\section{Language Form and Content Scales}

Descriptive statistics for performance on each of the four Language Form and Content scales are provided in Table 6 first for each syndrome and sex by syndrome, then for the full sample of children and each sex. To determine if performance on the CCC-2 Language Form and Content Scales differed significantly as a function of Scale and/or child Sex and/or Syndrome, a mixed ANOVA was conducted with Language Form and Content Scale (Speech, Syntax, Semantics, Coherence) as the within-subject factor and Sex and Syndrome as the between-subject factors. The Greenhouse-Geisser estimate of departure from sphericity was $\varepsilon=.86$. Using the Greenhouse-Geisser correction, the main 
effect of Form and Content Scale was significant, $F(2.581,771.84)=9.71, p<.001, \eta^{2}$ $=.03$. The main effect of Syndrome also was significant, $F(1,299)=6.27, p=.021 . \eta^{2}$ $=.02$. These main effects were tempered by a significant interaction between Scale and Syndrome, $F(2.581,771.84)=18.98, p<.001, \eta^{2}=.06($ see Figure 1$)$, and a significant interaction between Scale and Sex, $F(2.581,771.84)=3.21, p=.02, \eta^{2}=.01$ (see Figure 2). The effect of the three-way interaction between Scale, Syndrome, and Sex was not statistically significant, $F(2.581,771.84)=1.37, p=.25, \eta^{2}=.00$. The main effect of Sex also was not statistically significant, $F(1,299)=2.20, p=.14, \eta^{2}=.01$. 
Table 6

Descriptive Statistics for Parents' Ratings of the Performance of Children with Williams Syndrome or 7q11.23 Duplication Syndrome on the CCC-2 Language Form and Content Scales

\begin{tabular}{|c|c|c|c|c|c|c|c|c|c|c|c|c|c|c|}
\hline \multirow[b]{2}{*}{ Group } & \multirow[b]{2}{*}{ Sample } & \multirow[b]{2}{*}{$\mathrm{N}$} & \multicolumn{3}{|c|}{ Speech ScS } & \multicolumn{3}{|c|}{ Syntax ScS } & \multicolumn{3}{|c|}{ Semantics ScS } & \multicolumn{3}{|c|}{ Coherence ScS } \\
\hline & & & Mean & $\mathrm{SD}$ & Range & Mean & SD & Range & Mean & SD & Range & Mean & SD & Range \\
\hline \multicolumn{15}{|l|}{ WS } \\
\hline & Full Sample & 247 & 7.11 & 3.19 & $1^{a}-12$ & 6.82 & 3.39 & $1^{a}-13$ & 6.42 & 2.47 & $1^{a}-13$ & 5.60 & 2.49 & $1^{a}-13$ \\
\hline & Boys & 121 & 6.96 & 3.11 & $1^{a}-13$ & 6.49 & 3.32 & $1^{a}-12$ & 6.50 & 2.32 & $1^{\mathrm{a}}-13$ & 5.79 & 2.49 & $1^{\mathrm{a}}-13$ \\
\hline \multicolumn{15}{|l|}{ Dup7 } \\
\hline & Full Sample & 56 & 4.32 & 2.99 & $1^{a}-13$ & 6.20 & 3.39 & $1^{a}-12$ & 6.37 & 2.96 & $1^{a}-13$ & 5.57 & 2.55 & $1^{a}-13$ \\
\hline & Girls & 28 & 4.68 & 3.36 & $1^{\mathrm{a}}-12$ & 6.89 & 3.62 & $1^{a}-12$ & 7.21 & 2.79 & $3-13$ & 5.54 & 2.25 & $2-13$ \\
\hline & Boys & 28 & 6.96 & 2.60 & $1^{a}-8$ & 5.50 & 3.69 & $1^{a}-12$ & 5.54 & 2.94 & $1^{\mathrm{a}}-13$ & 5.61 & 2.86 & $1^{\mathrm{a}}-13$ \\
\hline \multicolumn{15}{|l|}{ Total } \\
\hline & Full Sample & 303 & 6.60 & 3.33 & $1^{a}-13$ & 6.71 & 3.45 & $1^{a}-12$ & 6.41 & 2.56 & $1^{a}-13$ & 5.59 & 2.49 & $1^{a}-13$ \\
\hline & Girls & 154 & 6.78 & 3.42 & $1^{a}-12$ & 7.10 & 3.46 & $1^{a}-12$ & 6.50 & 2.65 & $1^{a}-13$ & 5.44 & 2.43 & $1^{a}-13$ \\
\hline & Boys & 149 & 6.40 & 3.23 & $1^{a}-13$ & 6.30 & 3.40 & $1^{a}-12$ & 6.32 & 3.40 & $1^{a}-13$ & 5.76 & 2.55 & $1^{a}-13$ \\
\hline
\end{tabular}

Note. CCC-2 = Children's Communication Checklist-2; $\mathrm{ScS}$ = scaled score; WS = Williams syndrome; Dup7 = 7q11.23 duplication syndrome.

${ }^{a}$ Lowest possible scaled score. 


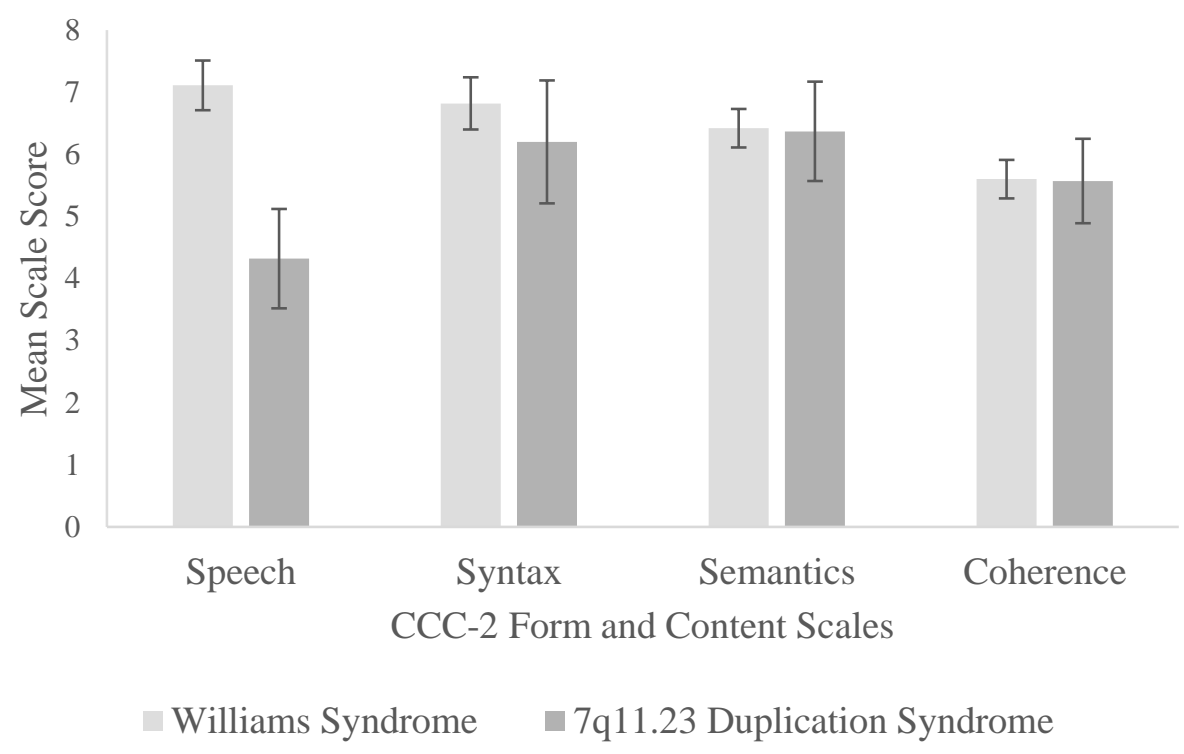

Figure 1. Mean scaled scores for the CCC-2 Form and Content scales for children with Williams syndrome and children with 7q11.23 duplication syndrome. Error bars indicate the $95 \%$ confidence intervals. 


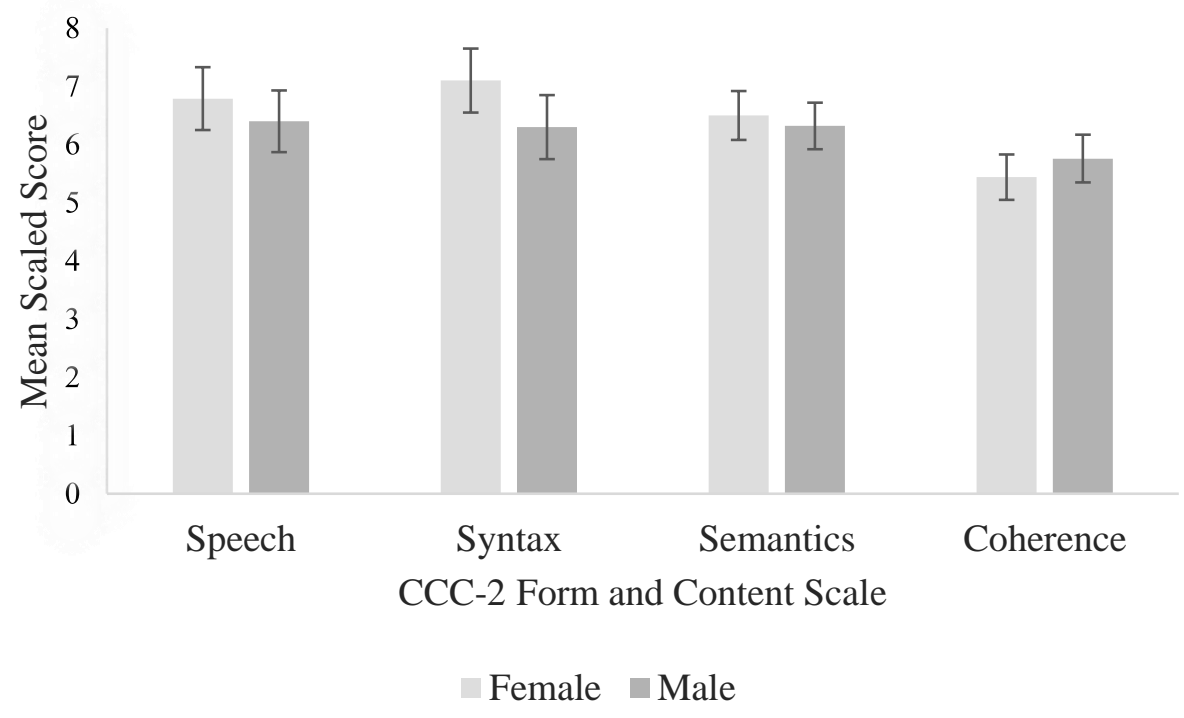

Figure 2. Mean scaled scores for children with Williams syndrome for the CCC-2 Form and Function scales as a function of sex. Error bars indicate the $95 \%$ confidence intervals.

The significant interaction between Scale and Syndrome was evaluated in two different ways. First, the pattern of significant effects was examined separately for each syndrome by conducting a separate one-way repeated measures ANOVA for each syndrome, with Form and Content Scale as the within-subject variable. For the ANOVA for children with WS, the Greenhouse-Geisser estimate of departure from sphericity was $\varepsilon=.84$. Using the Greenhouse-Geisser correction, the effect of Scale was statistically significant, $F(2.55,627.81)=26.25, p<.001, \eta^{2}=.10$. Multiple comparisons using the Sidak method, shown in Table 7, indicated that scaled scores for Speech, Syntax, and Semantics were all significantly higher than scaled scores for Coherence. In addition, scaled scores for Speech were significantly higher than scaled scores for Semantics. None of the other pairwise differences was significant. 
Table 7

$P$ values (Using Sidak Correction) and Cohen's d Values for Pairwise Comparisons of Scaled Scores on the CCC-2 Language Form and Content Scales as a Function of Syndrome

\begin{tabular}{|c|c|c|c|c|c|c|c|c|}
\hline \multirow[b]{2}{*}{ Syndrome } & \multirow[b]{2}{*}{ Scale } & \multirow[b]{2}{*}{ Mean } & \multicolumn{2}{|c|}{ Syntax } & \multicolumn{2}{|c|}{ Semantics } & \multicolumn{2}{|c|}{ Coherence } \\
\hline & & & $p$ & $d$ & $p$ & $d$ & $p$ & $d$ \\
\hline \multicolumn{9}{|l|}{ WS } \\
\hline & Speech & 7.11 & .436 & .09 & .001 & .24 & $<.001$ & .52 \\
\hline & Syntax & 6.82 & & & .247 & .13 & $<.001$ & .40 \\
\hline & Semantics & 6.42 & & & & & $<.001$ & .33 \\
\hline & Coherence & 5.60 & & & & & & \\
\hline \multicolumn{9}{|l|}{ Dup7 } \\
\hline & Speech & 4.32 & $<.001$ & .55 & $<.001$ & .69 & .015 & .45 \\
\hline & Syntax & 6.20 & & & .999 & .05 & .627 & .20 \\
\hline & Semantics & 6.38 & & & & & .057 & .30 \\
\hline & Coherence & 5.57 & & & & & & \\
\hline
\end{tabular}

Note. $\mathrm{WS}=$ Williams syndrome; Dup7 $=7 \mathrm{q} 11.23$ duplication syndrome

For the ANOVA for children with Dup7, the Greenhouse-Geisser estimate of departure from sphericity was $\varepsilon=.88$. Using the Greenhouse-Geisser correction, the effect of Scale was significant, $F(2.653,145.92)=10.66, p<.001, \eta^{2}=.16$. Sidak comparisons, shown in Table 7, indicated a different pattern of significant differences than had been found for children with WS. For children with Dup7, scaled scores for Syntax, Semantics, and Coherence were all significantly higher than scaled scores for 
Speech. None of the other pairwise comparisons between scaled scores was statistically significant.

To further evaluate the significant Scale X Syndrome interaction, four $t$-tests were conducted, one for each Form and Content scale, comparing the performance of children with WS to the performance of children with Dup7. To control for multiple analyses, $\alpha$ was set at $.0125(.05 / 4)$. Scaled scores for Speech were significantly higher for the WS group than the Dup7 group, $t(301)=5.99, p<.001, d=.90$. The between-syndrome difference in scaled scores was not statistically significant for the Syntax $[t(301)=1.23, p$ $=.221, d=.18]$, Semantics $[t(301)=0.12, p=.904, d=.01]$, or Coherence $[t(301)=$ $0.08, p=0.940, d=.01]$ scales.

To evaluate the significant interaction between Scale and Sex, I first conducted a separate one-way repeated measures ANOVA for each sex, with Language Form and Content Scale as the within-subject variable. For females, the Greenhouse-Geisser estimate of departure from sphericity was $\varepsilon=.85$. Using the Greenhouse-Geisser correction, the ANOVA indicated a significant effect of Scale, $F(2.56,392.11)=17.25$, $p$ $<.001, \eta^{2}=.10$. Multiple comparisons using the Sidak method, shown in Table 8, indicated that scaled scores for Speech, Semantics, and Syntax were significantly higher than scaled scores for Coherence. None of the remaining pairwise comparisons of scaled scores was statistically significant. 
Table 8

P values (Using Sidak Correction) and Cohen's d Values for Pairwise Comparisons of Scaled Scores on the CCC-2 Language Form and Content Scales as a Function of Sex

\begin{tabular}{|c|c|c|c|c|c|c|c|c|}
\hline \multirow[b]{2}{*}{ Sex } & \multirow[b]{2}{*}{ Scale } & \multirow[b]{2}{*}{ Mean } & \multicolumn{2}{|c|}{ Syntax } & \multicolumn{2}{|c|}{ Semantics } & \multicolumn{2}{|c|}{ Coherence } \\
\hline & & & $p$ & $d$ & $p$ & $d$ & $p$ & $d$ \\
\hline \multicolumn{9}{|c|}{ Female } \\
\hline & Speech & 6.79 & .786 & .09 & .863 & .16 & $<.001$ & .45 \\
\hline & Syntax & 7.10 & & & .110 & .20 & $<.001$ & .54 \\
\hline & Semantics & 6.50 & & & & & $<.001$ & .42 \\
\hline & Coherence & 5.44 & & & & & & \\
\hline \multicolumn{9}{|c|}{ Male } \\
\hline & Speech & 6.40 & .999 & .03 & 1.0 & .03 & .067 & .22 \\
\hline & Syntax & 6.30 & & & 1.0 & .01 & .154 & .18 \\
\hline & Semantics & 6.32 & & & & & .006 & .23 \\
\hline & Coherence & 5.76 & & & & & & \\
\hline
\end{tabular}

Note. $\mathrm{ScS}=$ scaled score

For males, the Greenhouse-Geisser estimate of departure from sphericity was $\varepsilon$ $=.84$. Using the Greenhouse-Geisser correction, the ANOVA indicated a significant effect of Scale, $F(2.53,374.93)=3.18, p=.031, \eta^{2}=.02$. Multiple comparisons using the Sidak method, shown in Table 8, indicated that scaled scores for Semantics were significantly higher than scaled scores for Coherence. None of the other pairwise comparisons of scaled scores was statistically significant. 
To further evaluate the significant Scale by Sex interaction, four $t$-tests were conducted, one for each Language Form and Content scale, comparing the performance of females to the performance of males. To control for multiple analyses, $\alpha$ was set at $.0125(.05 / 4)$. The between-sex difference was not statistically significant for any of these scales [for Speech, $t(301)=1.04, p=.301, d=.12$; for Syntax, $t(301)=2.02, p$ $=.044, d=.23$; for Semantics, $t(301)=0.60, p=.547, d=.07$; for Coherence, $t(301)=$ $1.13, p=.260, d=.13]$.

\section{Pragmatic Communication Scales}

Descriptive statistics for performance on each of the four Pragmatic Communication scales are provided in Table 9 first for each syndrome and sex by syndrome, then for the full sample of children and each sex. To determine if performance on the CCC-2 Pragmatic Communication Scales differed significantly as a function of Scale and/or child Sex and/or Syndrome, a mixed ANOVA was conducted with Pragmatic Communication Scale (Initiation, Scripted Language, Context, Nonverbal Communication) as the within-subject factor and Sex and Syndrome as the betweensubject factors. The Greenhouse-Geisser estimate of departure from sphericity was $\varepsilon$ $=.97$. Using the Greenhouse-Geisser correction, the main effect of Pragmatic Communication Scale was significant, $F(2.918,872.392)=30.28, p<.001, \eta^{2}=.09$. This main effect was tempered by a significant interaction between Scale and Syndrome, $F(2.918,872.392)=19.49, p<.001, \eta^{2}=.06($ see Figure 3). The main effect of Syndrome was not statistically significant, $F(1,299)=2.24, p=.136 . \eta^{2}=.007$. However, the main effect of Sex was statistically significant, $F(1,299)=4.10, p=.044$, $\eta^{2}=.01$, with females earning significantly higher Pragmatic Communication Language 
scaled scores $(M=6.24)$ than males $(M=5.65), d=.28$. The interaction between Scale and Sex, $F(2.918,872.392)=1.16, p=.325, \eta^{2}=.00$ and the three-way interaction between Scale, Syndrome, and Sex, $F(2.918,872.392)=1.84, p=.140, \eta^{2}=.01$, were not statistically significant. 
Table 9

Descriptive Statistics for Parents' Ratings of the Performance of Children with Williams Syndrome or 7q11.23 Duplication Syndrome on the CCC-2 Pragmatic Scales

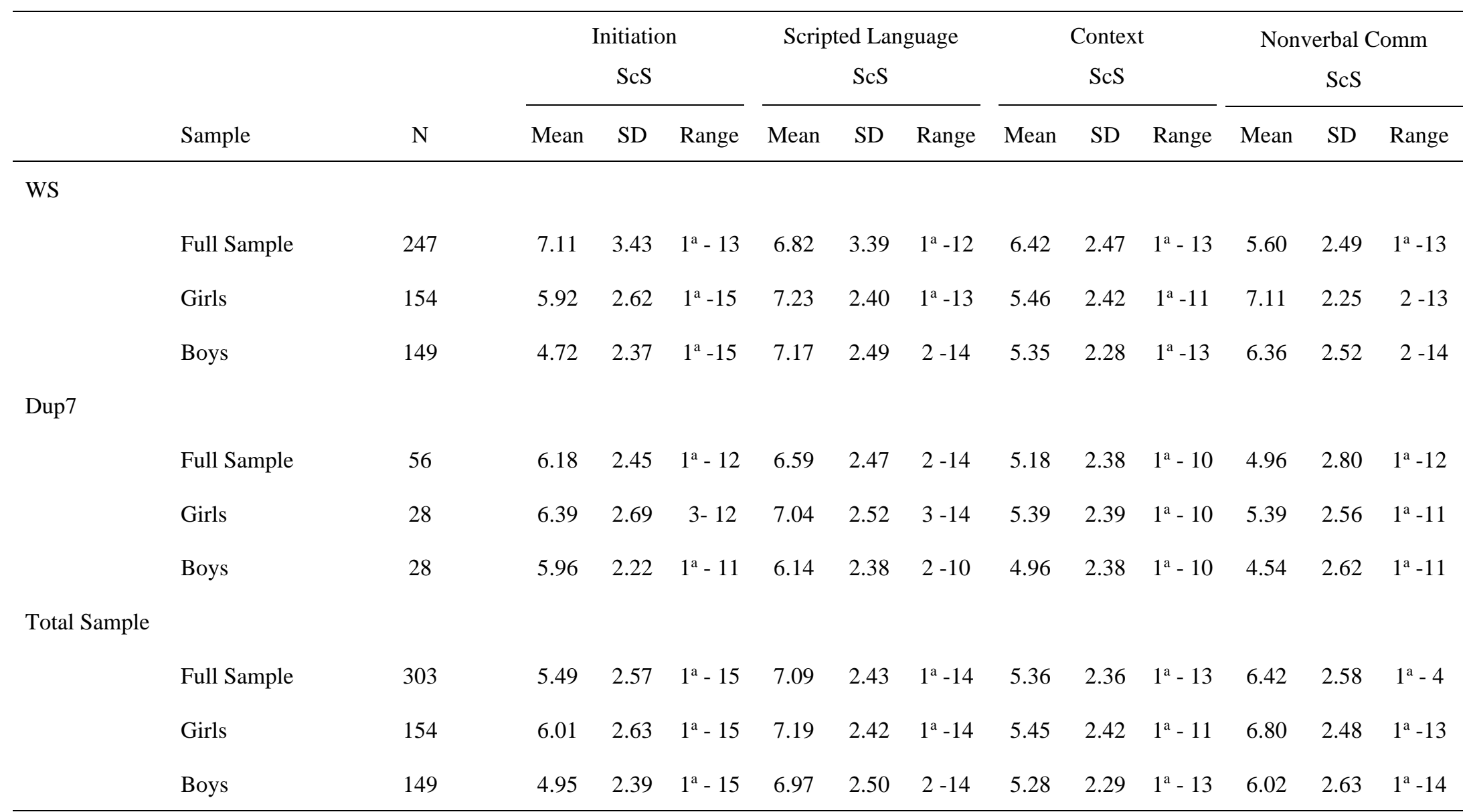

Note. CCC-2 = Children's Communication Checklist-2; $\mathrm{ScS}=$ scaled score; WS = Williams syndrome; Dup7 = 7q11.23 duplication syndrome; Comm. =

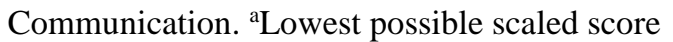




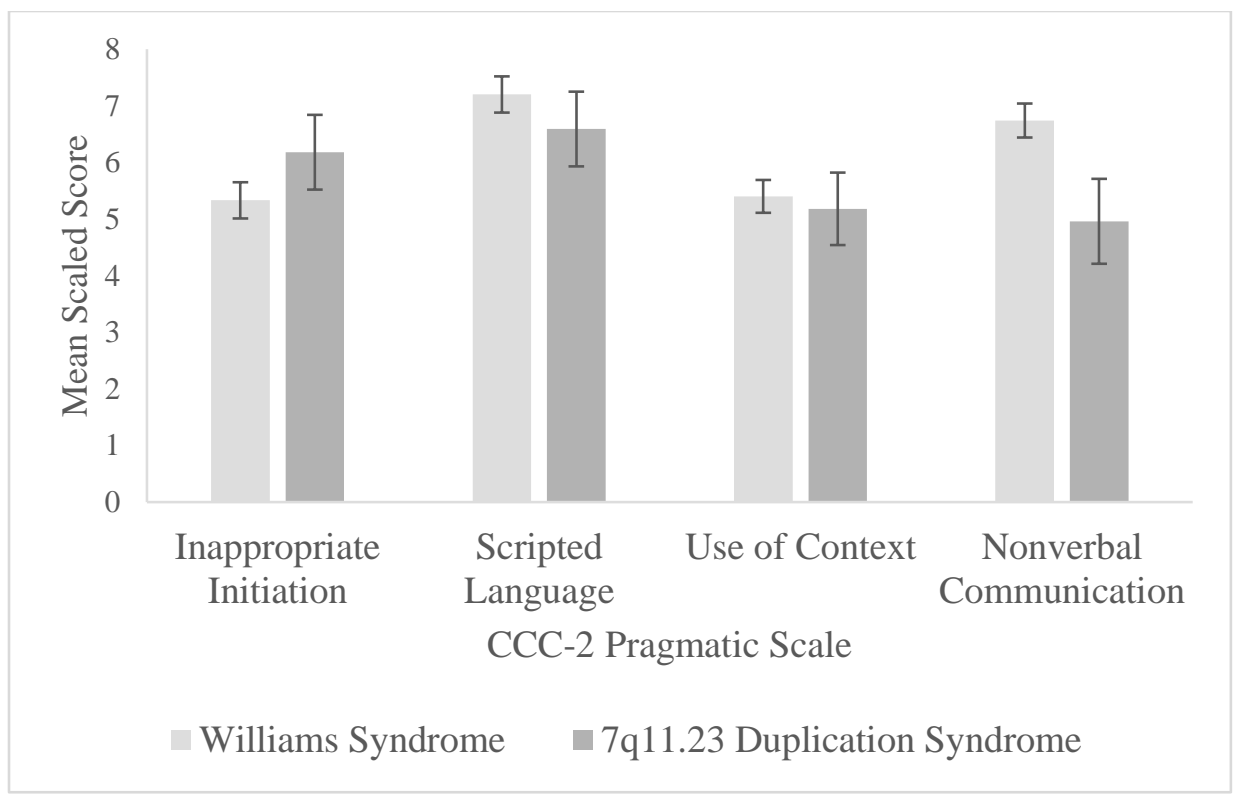

Figure 3. Mean scaled scores for the CCC-2 Pragmatic Communication scales for children with Williams syndrome and children with 7q11.23 duplication syndrome. Error bars indicate the $95 \%$ confidence intervals

The significant interaction between Scale and Syndrome was evaluated in two different ways. First, the pattern of significant effects was examined separately for each syndrome by conducting a separate one-way repeated measure ANOVA for each syndrome, with Pragmatic Communication Scale as the within-subject variable. For the ANOVA for children with WS, the Greenhouse-Geisser estimate of departure from sphericity was $\varepsilon=.96$. Using the Greenhouse-Geisser correction, the effect of Scale was significant, $F(2.887,710.103)=81.01, p<.001, \eta^{2}=.25$. Multiple comparisons using the Sidak method, shown in Table 10, indicated that scaled scores for Scripted Language were significantly higher than scaled scores for Initiation, Context, and Nonverbal Communication. In addition, scaled scores for Nonverbal Communication were 
significantly higher than scaled scores for Initiation and Context. None of the other pairwise differences was significant.

Table 10

$P$ values (using Sidak Correction) and Cohen's d Values for Pairwise Comparisons of Scaled Scores on CCC-2 Pragmatic Scales as a function of Syndrome

\begin{tabular}{|c|c|c|c|c|c|c|c|c|}
\hline \multirow[b]{2}{*}{ Syndrome } & \multirow[b]{2}{*}{ Scale } & \multirow[b]{2}{*}{ Mean } & \multicolumn{2}{|c|}{$\begin{array}{l}\text { Scripted } \\
\text { Language }\end{array}$} & \multicolumn{2}{|c|}{ Context } & \multicolumn{2}{|c|}{$\begin{array}{c}\text { Nonverbal } \\
\text { Comm. }\end{array}$} \\
\hline & & & $p$ & $d$ & $p$ & $d$ & $p$ & $d$ \\
\hline \multicolumn{9}{|l|}{ WS } \\
\hline & Initiation & 5.33 & $<.001$ & .75 & .997 & .03 & $<.001$ & .57 \\
\hline & Scripted & 7.20 & & & $<.001$ & .75 & .013 & .19 \\
\hline & Language & & & & & & & \\
\hline & Context & 5.41 & & & & & $<.001$ & .56 \\
\hline & Nonverbal & 6.75 & & & & & & \\
\hline & Comm. & & & & & & & \\
\hline \multicolumn{9}{|l|}{ Dup7 } \\
\hline & Initiation & 6.18 & .812 & .17 & .039 & .41 & .007 & .46 \\
\hline & Scripted & 6.59 & & & $<.001$ & .58 & $<.001$ & .61 \\
\hline & Language & & & & & & & \\
\hline & Context & 5.18 & & & & & .998 & .08 \\
\hline & Nonverbal & 4.96 & & & & & & \\
\hline & Comm. & & & & & & & \\
\hline
\end{tabular}

For the ANOVA for children with Dup7, the Greenhouse-Geisser estimate of departure from sphericity was $\varepsilon=.97$. Using the Greenhouse-Geisser correction, the 
effect of Scale was significant, $F(2.894,159.15)=10.66, p<.001, \eta^{2}=.16$. Sidak comparisons, shown in Table 9, indicated a pattern of significant differences that partially overlapped the pattern that was found for children with WS. For children with Dup7, scaled scores for both Initiation and Scripted Language were significantly higher than scaled scores for Context and Nonverbal Communication. None of the other pairwise comparisons between scaled scores was statistically significant.

To further evaluate the significant Scale X Syndrome interaction, four $t$-tests were conducted, one for each Pragmatic Communication scale, comparing the performance of children with WS to the performance of children with Dup7. To control for multiple analyses, $\alpha$ was set at $.0125(.05 / 4)$. Scaled scores for Nonverbal Communication were significantly higher for the WS group than the Dup7 group, $t(301)=4.84, p<.001, d$ $=.72$. The between-syndrome difference in scaled scores was not statistically significant for the Initiation $[t(301)=2.24, p=.026, d=.33]$, Scripted Language $[t(301)=1.68, p$ $=.094, d=.25]$, or Context $[t(301)=0.65, p=0.52 d=.10]$ scales.

\section{Comparison of Language Form and Content and Pragmatic Communication Ability}

To determine if there was a significant difference between the CCC-2 mean scaled score for the Language Form and Content Scales (Speech, Syntax, Semantics, Coherence) and the CCC-2 mean scaled score for the Pragmatic Communication Scales (Initiation, Scripted Language, Context, Nonverbal Communication) as a function of Sex and/or Syndrome, a mixed ANOVA was conducted with CCC-2 Component (mean Language Form and Content Scale scaled score, mean Pragmatic Communication Scale scaled score) as the within-subject factor and Sex and Syndrome as the between-subject factors. The main effect of mean scaled score was not statistically significant, $F(1.299)=.69, p$ 
$=.097, \eta^{2}=.00$. The main effect of Syndrome was statistically significant, $F(1,299)=$ 4.92, $p=.027 . \eta^{2}=.016$, with children with WS $(M=6.33)$ scoring significantly higher than children with Dup7 $(M=5.67)$. The interaction between Syndrome and Scale was not significant, $F(1,299)=2.92, p=.089, \eta^{2}=.01$. The main effect of Sex was not statistically significant, $F(1,299)=3.52, p=.061, \eta^{2}=.01$. The interaction between Scale and Sex, $F(1,299)=0.89, p=.767, \eta^{2}=.00$ and the three-way interaction between Scale, Syndrome, and Sex, $F(2.918,872.392)=1.92, p=.167, \eta^{2}=.01$, also were not statistically significant.

\section{Autism-related Scales}

Descriptive statistics for performance on the CCC-2 Autism-related scales are provided in Table 11 first for each syndrome and then for each sex and finally for the full sample and for each sex. To determine if performance on the CCC-2 Autism-related scales differed significantly as a function of Scale and/or Sex and/or Syndrome, a mixed ANOVA was conducted with Autism-related Scale (Social Relations, Interests) as the within-subject factor and Sex and Syndrome as the between-subject factors. The main effect of Autism-related Scale was significant, $F(1,299)=13.89, p<.001, \eta^{2}=.04$. The main effect of Syndrome also was significant, $F(1,299)=8.09, p=.005 . \eta^{2}=.03$. These main effects were tempered by a significant interaction between Scale and Syndrome, $F(1,299)=77.73, p<.001, \eta^{2}=.21$ (see Figure 4). The main effect of Sex also was statistically significant, $F(1,299)=17.55, p<.001, \eta^{2}=.06$, with females $(M=7.50)$ earning significantly higher scaled scores than males $(M=6.10), d=.54$. The interaction between Scale and Sex was not statistically significant, $F(1,299)=1.09, p=.297, \eta^{2}$ 
$=.00$. The effect of the three-way interaction between Scale, Syndrome, and Sex also was not statistically significant, $F(1,299)=3.30, p=.070, \eta^{2}=.01$.

Table 11

Descriptive Statistics for the Parents' Ratings of the Performance of Children with Williams Syndrome or 7q11.23 Duplication Syndrome on the CCC-2 Autism-related Scales

\begin{tabular}{|c|c|c|c|c|c|c|c|c|}
\hline & \multirow[b]{2}{*}{ Sample } & \multirow[b]{2}{*}{$\mathrm{N}$} & \multicolumn{3}{|c|}{ Social Relations ScS } & \multicolumn{3}{|c|}{ Interests ScS } \\
\hline & & & Mean & SD & Range & Mean & SD & Range \\
\hline \multirow[t]{3}{*}{ WS } & Full Sample & 247 & 7.75 & 2.44 & $3-13$ & 6.82 & 2.86 & $1^{a}-16$ \\
\hline & Girls & 126 & 8.04 & 2.31 & $3-13$ & 7.63 & 2.80 & $1^{a}-15$ \\
\hline & Boys & 121 & 7.45 & 2.55 & $3-13$ & 5.98 & 2.69 & $1^{\mathrm{a}}-16$ \\
\hline \multirow[t]{3}{*}{ Dup7 } & Full Sample & 56 & 5.16 & 2.63 & $1^{\mathrm{a}}-13$ & 7.48 & 2.69 & $2-13$ \\
\hline & Girls & 28 & 6.07 & 2.52 & $1^{\mathrm{a}}-12$ & 8.21 & 2.82 & $3-13$ \\
\hline & Boys & 28 & 4.25 & 2.46 & $1^{\mathrm{a}}-11$ & 6.71 & 2.34 & $2-11$ \\
\hline \multirow[t]{3}{*}{ Total } & Full Sample & 303 & 7.27 & 2.67 & $1^{\mathrm{a}}-13$ & 6.94 & 2.84 & $1^{\mathrm{a}}-16$ \\
\hline & Girls & 154 & 7.68 & 2.46 & 3- 13 & 7.74 & 2.81 & $1^{a}-15$ \\
\hline & Boys & 149 & 6.85 & 2.82 & $1^{\mathrm{a}}-13$ & 6.11 & 2.63 & $1^{\mathrm{a}}-16$ \\
\hline
\end{tabular}

Note. CCC-2 = Children's Communication Checklist-2; $\mathrm{ScS}=$ scaled score; WS = Williams syndrome; Dup7 = 7q11.23 duplication syndrome.

${ }^{\mathrm{a}}=$ Lowest possible scaled score.

The significant interaction between Scale and Syndrome was evaluated in two different ways. First, the pattern of differences between scaled scores on the two Autismrelated scales was examined separately for each syndrome by conducting a paired samples $t$-test. For the children with WS, the difference between scaled scores was statistically significant, $t(246)=5.69, p<.001, d=.35$, with scaled scores for Social 
Relations significantly higher than scaled scores for Interests. For the children with Dup7, the difference also was statistically significant, $t(55)=-7.29, p<.001, d=.88$. However, the pattern was the opposite of that for children with WS. For children with Dup7, scaled scores for Interests were significantly higher than scaled scores for Social Relations.

To further evaluate the significant Scale X Syndrome interaction, two independent sample $t$-tests were conducted, one for each Autism-related scale, comparing the performance of children with WS to the performance of children with Dup7. To control for multiple analyses, $\alpha$ was set at $.025(.05 / 2)$. Scaled scores for Social Relations were significantly higher for the WS group than the Dup7 group, $\mathrm{t}(301)=7.06, p<.001$, $d=1.05$, as shown in Figure 4 . The between-syndrome difference was not statistically significant for the Interests scale, $t(301)=1.59, p=.114, d=.24$ (Figure 4).

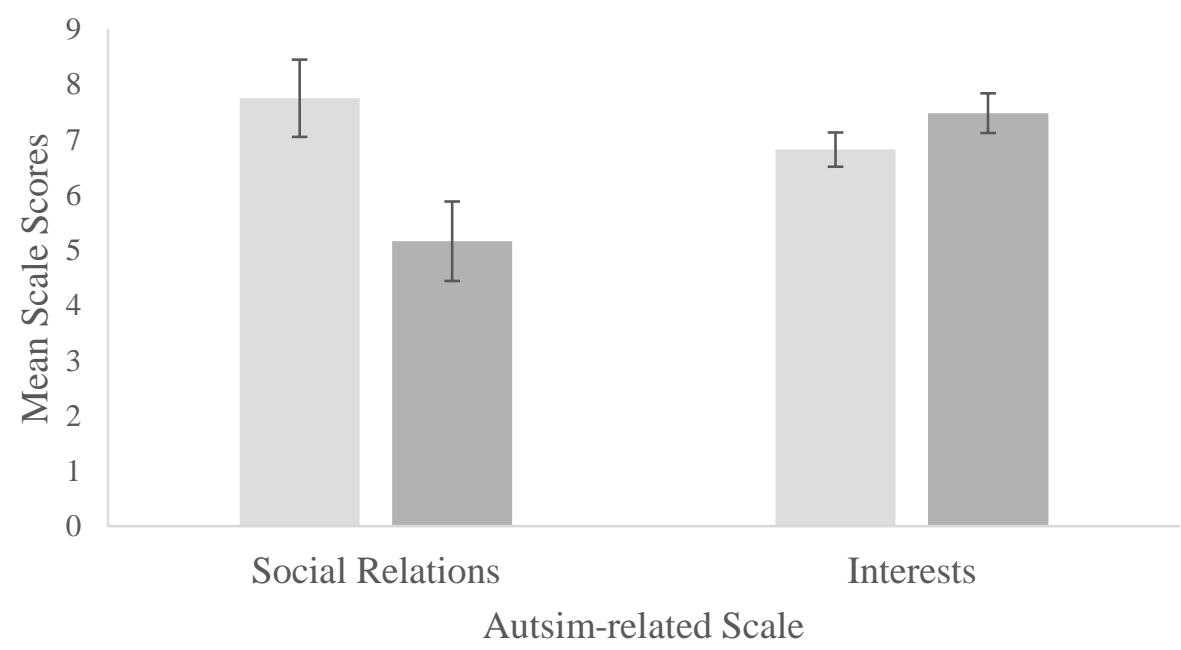

घilliams Syndrome $\quad$ 7q11.23 Duplication Syndrome

Figure 4. Mean scaled scores for the CCC-2 Autism-related scales for children with Williams syndrome and children with 7q11.23 duplication syndrome. Error bars indicate the $95 \%$ confidence intervals. 


\section{Research Question 3: Concurrent Predictors of Pragmatic Communication}

The third goal was to determine the concurrent predictors of pragmatic

communication ability for each of the two syndromes. To address this goal, two separate multiple linear regressions were performed. CCC-2 Pragmatic Communication mean scaled score was the dependent variable. The independent variables were CA, CCC-2 Language Form and Content mean scaled score, KBIT-2 Nonverbal SS, BRIEF-2 BRI and ERI mean $T$-score, and Sex.

\section{Predictors of Pragmatic Communication Ability: Children with Williams Syndrome}

Descriptive statistics for children with WS for the variables included in the regression are reported in Table 12. Bivariate correlations between these variables are shown in Table 13. All correlations were significant except for the correlation between KBIT-2 NV SS and mean BRI \& ERI $T$-score.

The model described above explained a large amount of the variance in CCC-2 Pragmatic Communication mean scaled score, $R^{2}=.64$, adjusted $R^{2}=.64, F(5,246)=$ 87.14, $p<.001$. As indicated in Table 14, all independent variables except Nonverbal Reasoning contributed to the model significantly. The effect size was small for CA (uniquely accounting for $0.67 \%$ of the variance in the Pragmatic Communication variable) and Biological Sex (uniquely accounting for $1.46 \%$ of the variance), medium for BRI and ERI mean $T$-score (uniquely accounting for $10.96 \%$ of the variance), and large for Language Form and Content (uniquely accounting for $22.66 \%$ of the variance). 
Table 12

Descriptive Statistics for the Continuous Variables Included in the Regression Analyses: Children with Williams Syndrome

\begin{tabular}{lrrrc}
\hline Measure & Mean & Median & SD & Range \\
\hline CCC-2 Pragmatic Communication Mean ScS & 6.17 & 6.25 & 1.99 & $2-13.50$ \\
Chronological Age & 10.57 & 10.28 & 2.96 & $6-15.50$ \\
KBIT-2 Nonverbal SS & 76.04 & 77.00 & 16.23 & $40-116$ \\
CCC-2 Language Form and Content Mean ScS & 6.49 & 6.50 & 2.33 & $1^{\mathrm{a}}-12.50$ \\
BRIEF-2 BRI and ERI mean T-score & 68.88 & 64.00 & 9.52 & $40.5-90$ \\
\hline
\end{tabular}

Note. CCC-2 = Children's Communication Checklist-2; ScS = scaled score; KBIT-2 =

Kaufman Brief Intelligence Test - 2; BRIEF-2 = Behavior Rating Inventory of Executive

Functioning $-2 ;$ BRI = Behavior Regulation Index; ERI = Emotion Regulation Index.

${ }^{a}$ Lowest possible scaled score.

Table 13

Correlations for Parent Ratings of the Performance of Children with Williams Syndrome on the Regression Variables

\begin{tabular}{llllll}
\hline Scale & 1 & 2 & 3 & 4 & 5
\end{tabular}

1. CCC-2 Pragmatic Comm $M$ ScS

2. Chronological Age $\quad .07$

3. Sex

$.13-.11$

4. CCC-2 Form and Content $M \mathrm{ScS}$

$.72 * * \quad .12 \quad-.02$

5. KBIT NV SS

$\begin{array}{llll}.30 * * & -.06 \quad .02 & .40 * *\end{array}$

6. Mean BRI/ERI $T$ score

$.58 * * \quad-.20$

$-.06$

$.39 * * \quad .09 * *$

Note $. \mathrm{NV}=$ Nonverbal; $\mathrm{SS}=$ Standard Score CCC-2 = Children's Communication

Checklist; KBIT = Kaufman Brief Intelligence Test; BRI = Behavior Regulation Index;

ERI $=$ Emotion Regulation Index $;$ Comm = Communication; $M=$ Mean; $\mathrm{ScS}=$ scaled score

${ }^{* *} p \leq .001$ 
Table 14

Multiple Regression Analysis Predicting Concurrent Pragmatic Communication Abilities for

Children with Williams Syndrome as Measured by the Children's Communication Checklist -2

Mean Pragmatic Communication Scaled Score

\begin{tabular}{lcccccc}
\hline Predictor & $B$ & $t$ & $p$ & $95 \%$ CI for & $\begin{array}{c}\text { Semi- } \\
\text { partial } r\end{array}$ & $f^{2}$ \\
\hline Constant & & & & $B$ & Cohen's \\
Chronological Age & 5.92 & 16.83 & $<.001$ & $5.23-6.11$ & & \\
Sex & -.06 & -2.15 & .03 & $.11-.01$ & .08 & .02 \\
KBIT NV SS & .48 & 3.15 & .002 & $.18-.79$ & .12 & .04 \\
CCC-2 Form and Content $M$ ScS & .48 & 12.37 & $<.001$ & $.41-.56$ & .48 & .63 \\
Mean BRI/ERI T score & -.08 & -8.62 & $<.001$ & $-.09--.06$ & -.33 & .31 \\
\hline
\end{tabular}

Note. KBIT NV SS = Kaufman Brief Intelligence Test-2 Nonverbal standard score; CCC-2

Form and Content $M \mathrm{ScS}=$ mean of the Children's Communication Checklist-2 Form and

Content scaled scores; Mean BRI/ERI $T$ score = mean of the Behavior Rating Inventory of

Executive Function-2 Behavior Regulation Index and Emotion Regulation Index.

\section{Predictors of Pragmatic Communication Ability: Children with 7q11.23 Duplication}

\section{Syndrome}

Descriptive statistics for the variables included in the regression are reported in

Table 15. Bivariate correlations between these variables are shown in Table 16. All

correlations were significant except for the correlation between KBIT-2 NV SS and CCC-

2 Pragmatic Communication mean scaled score and the correlation between KBIT-2 NV

SS and mean BRI and ERI $T$-score. The model described above explained a large

amount of the variance in CCC-2 Pragmatic Communication mean scaled score, $R^{2}=.60$,

adjusted $R^{2}=.56, F(5,50)=15.16, p<.001$. All independent variables except KBIT-2

NV SS and Sex contributed significantly to the model (Table 17). The effect size was 
medium for CA (uniquely accounting for $13.54 \%$ of the variance in the Pragmatic Communication variable) and mean BRI and ERI $T$-score (uniquely accounting for $12.32 \%$ of the variance) and large for Language Form and Content (uniquely accounting for $24.40 \%$ of the variance).

Table 15

Descriptive Statistics for the Continuous Variables Included in the Regression Analyses: Children with 7q11.23 Duplication Syndrome

\begin{tabular}{lcccc}
\hline Measure & Mean & Median & SD & Range \\
\hline CCC-2 Pragmatic Communication Mean ScS & 5.73 & 5.63 & 2.00 & $2.25-10.25$ \\
Chronological Age & 10.33 & 10.20 & 2.82 & $6.08-15.28$ \\
KBIT-2 Nonverbal SS & 89.88 & 89.00 & 18.12 & $50-123$ \\
CCC-2 Language Form and Content Mean ScS & 5.62 & 5.63 & 2.46 & $1^{\mathrm{a}}-10.25$ \\
BRIEF-2 BRI and ERI mean T-score & 67.61 & 69.00 & 10.77 & $43.5-86.5$ \\
\hline
\end{tabular}

Note. CCC-2 = Children's Communication Checklist-2; $\mathrm{ScS}=$ scaled score. $\mathrm{NV}=$ Nonverbal; SS = Standard Score; CCC-2 = Children's Communication Checklist; KBIT = Kaufman Brief Intelligence Test; Mean BRI/ERI $T$ score = mean of the Behavior Rating Inventory of Executive Function-2 Behavior Regulation Index and Emotion Regulation Index; $\mathrm{ScS}=$ scaled score

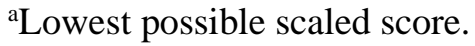


Table 16

Correlations for Parent Ratings of the Performance of Children with 7q11.23 Duplication Syndrome on the Regression Variables

\begin{tabular}{lccccc}
\hline \multicolumn{1}{c}{ Predictor } & 1 & 2 & 3 & 4 & 5 \\
\hline 1.CCC-2 Pragmatic Comm $M S c S$ & & & & & \\
2. Sex & -.17 & & & & \\
3. Chronological Age & -.14 & .05 & & & \\
4. CCC-2 Form and Content $M S c S$ & $.59^{* *}$ & $.33^{*}$ & $.33^{*}$ & & \\
5. KBIT NV SS & .20 & -.26 & .22 & & \\
6. Mean BRI/ERI $T$ score & $.50^{* *}$ & -.06 & -.17 & $-.35^{* *}$ & -.18 \\
\hline
\end{tabular}

Note. $\mathrm{NV}=$ Nonverbal; $\mathrm{ScS}=$ scaled score; $\mathrm{SS}=$ Standard Score; CCC-2 = Children's Communication Checklist; KBIT = Kaufman Brief Intelligence Test; BRI = Behavior Regulation Index; ERI = Emotion Regulation Index; Comm $=$ Communication; $M=$ Mean ${ }^{* *} p \leq .001$ 


\section{Table 17}

Multiple Regression Analysis Predicting Pragmatic Concurrent Communication Abilities for Children with 7q11.23 Duplication Syndrome as Measured by the Children's Communication Checklist-2 Mean Pragmatic Communication Scaled Score

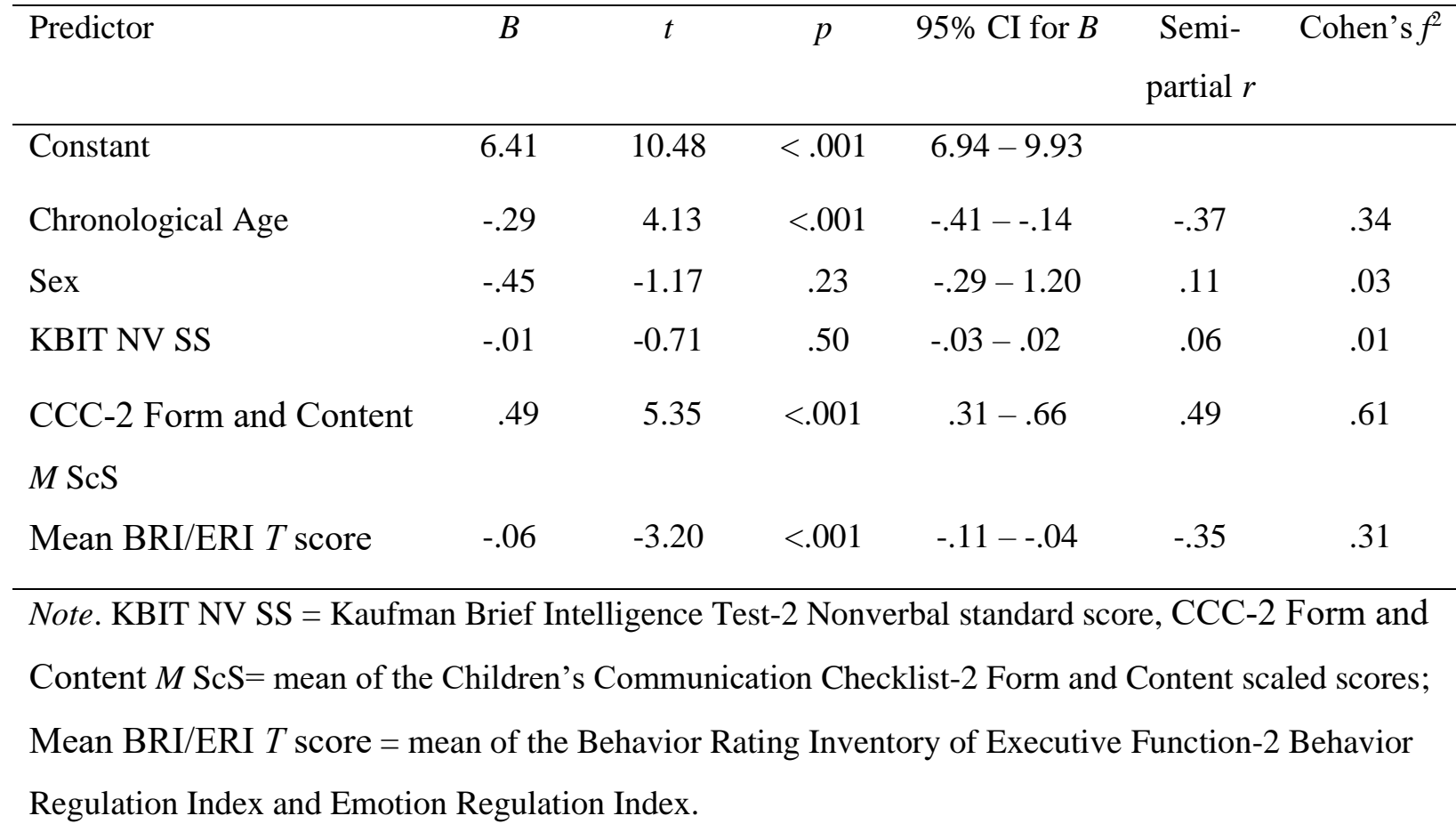




\section{CHAPTER IV}

\section{DISCUSSION}

Gaining increased knowledge on pragmatic development is beneficial to help children with developmental disabilities such as WS and Dup7. Pragmatic communication is defined by Berko-Gleason (2005) as the use of language to express one's intentions and get things done in the world. It is the use of language in social contexts. Difficulties in pragmatic communication can affect the educational setting, home setting, and friendship settings. The effects of deficits in pragmatic communication can often be seen in ASD (e.g., Baron-Cohen, 1988; Parsons, Cordier, Munro, Joosten \& Speyer, 2017; Rodas, Eisenhowe \& Blacher, 2017; Tager-Flusberg, 1981).

The dissertation had three main goals. The first goal was to examine the overall level of language and communication ability as measured by the CCC-2 for children with WS and children with Dup7 relative to CA expectations. The second goal was to determine the pattern of relative strengths and weaknesses in language form and content, pragmatic communication, and ASD-related behaviors for both children with WS and children with Dup7 and to compare these patterns. The final goal was to identify the concurrent predictors of pragmatic communication ability for children with each of the two syndromes. In the remainder of this chapter, I summarize and discuss the implications of these findings and consider the limitations of the project and future directions for research. 


\section{Research Question 1: Overall Language Performance}

The first goal of this dissertation was to examine the overall level of language and communication ability as measured by the CCC-2 for children with WS and children with Dup7 relative to CA expectations. For both groups, the mean CCC-2 composite SS was in the language impairment range. Although there was considerable variability in CCC-2 composite SSs within each group, more than $60 \%$ of children with each syndrome were classified as having a language impairment. The mean CCC-2 composite SS was slightly but significantly higher for the children with WS than the children with Dup7. This is striking since the Dup7 group's mean IQ was about 20 points higher than the WS group's, and the Verbal IQ for the Dup7 group also was significantly higher than the Verbal IQ for the WS group. The current findings for WS are consistent with previous studies with smaller samples involving the CCC or the CCC-2 (Hoffman et al., 2013; Laws \& Bishop, 2004; Philofsky et al., 2007) in the level of impairment and variability present.

The SIDI scores demonstrated that for most of the children in each group pragmatic communication ability was in the range of form and content language ability. The two groups did not differ significantly in SIDI score. The overall pattern of SIDI scores for both syndromes was a normal bell-shaped curve, with most children performing in the normal range, a pattern like that for TD children. This study confirms the findings of other studies of children with WS (Hoffman et al., 2013; Philofsky et al., 2007) which also showed that the mean SIDI was close to 0 indicating no significant difference in pragmatic and form and content language ability. 


\section{Research Question 2: Patterns of Relative Strengths and Weaknesses}

The second research goal was to determine if there were patterns of relative strengths and weaknesses on each component of the CCC-2 for each syndrome. Patterns were identified for each syndrome, for each CCC-2 component, as summarized below.

\section{Language Form and Content}

For children with WS, Coherence was found to be a significant relative weakness compared to the other Form and Content Scales (Speech, Syntax, and Semantics). This finding is consistent with Laws and Bishop (2004) who reported that children with WS have a nominal weakness in the Coherence scale relative to the other Form and Content scales. Philofsky and Fidler (2007) also found that Coherence was a nominal weakness relative to Speech and Syntax for children with WS.

Children with Dup7 demonstrate a different Form and Content profile, with a significant relative weakness on the Speech scale when compared to Syntax, Semantics, and Coherence. Furthermore, children with Dup7 earned a significantly lower scaled score than children with WS on the Speech scale. This finding is consistent with the results obtained by Huffman (2019) using an examiner-administered measure of speech articulation, the Goldman-Fristoe Test of Articulation-2 (GFTA-2; Goldman \& Fristoe, 2000). Huffman found that despite having higher significantly higher IQs than the children with WS, the children with Dup7 scored significantly lower on the GFTA-2.

\section{Pragmatic Communication}

The Pragmatic Communication patterns of relative strengths and weaknesses partially overlapped for the WS and Dup7 groups. For children with WS, Initiation and Use of Context were significantly weaker than Scripted Language and Nonverbal 
Communication. Laws and Bishop (2004) as well as Philofsky and Fidler (2007) found that children with WS have nominal difficulty with Inappropriate Initiation and Use of Context relative to Scripted Language and Nonverbal Communication. It has also been previously shown in studies not using the CCC or CCC-2 that children with WS talk frequently about irrelevant topics, have poor turn taking skills, are overly friendly and inappropriately approach strangers, fail to add adequate information to a conversation, and have trouble with topic maintenance (e.g., Dilts et al., 1990; Gosch \& Pankau, 1997; Meyerson \& Frank, 1987; Semel \& Rosner, 2003; Stojanovik, Perkins, \& Howard, 2001; Tomc et al., 1990; Udwin \& Yule, 1991). This finding also is consistent with previous work indicating that young children with WS demonstrate a relative strength in emotional responsivity and increased imitation of affect (Fidler, Hepburn, Most, Philofsky \& Rogers, 2007).

The Pragmatic Communication pattern for children with Dup7 overlapped that for children with WS. For children with Dup7, Initiation and Scripted Language scaled scores were significantly higher than scaled scores for Use of Context and Nonverbal Communication. The children with Dup7 also earned significantly lower scaled scores than the children with WS on the Nonverbal Communication scale. Based on findings from the ADOS-2 assessment, Klein-Tasman and Mervis (2018) found that more than half of the participants with Dup7 scored within normal limits on the scripted language/stereotyped language items.

\section{Autism-related Scales}

The two syndromes demonstrated opposite patterns on the Autism-related scales: The children with WS evidenced a relative strength on Social Relations and a relative 
weakness on Interests, whereas the children with Dup7 had a relative strength on Interests and a relative weakness on Social Relations. Other studies have demonstrated the repetitive preoccupation or obsessions present in WS (Janes et al., 2014; Klein-Tasman, van der Fluit \& Mervis, 2018; Rodgers, Riby, Janes, Connolly \& McConachie, 2012); the majority of children with Dup7 did not evidence difficulty with preoccupations or obsessions during the ADOS-2 (Klein-Tasman \& Mervis, 2018). Previous studies have indicated children with Dup7 are less engaging and use less eye contact around strangers, perhaps due to social anxiety (Mervis et al., 2015; Velleman \& Mervis, 2011). In contrast, children with WS are affectively attuned to others and are highly engaged with their social partners (Klein-Tasman \& Mervis, 2003).

In addition, there was a main effect of Sex with females scoring higher than males on the Autism-related scales. This pattern is congruent with other studies showing a higher male: female ratio of children with ASD (e.g., Fombonne, 2009; Werling \& Geschwind, 2013).

\section{Research Question 3: Concurrent Predictors of Pragmatic Communication}

An examination of the correlations of the independent variables included in the regression analyses indicated that for both children with WS and children with Dup7, pragmatic communication ability was significantly related to language form and content ability. This relation has previously been reported for children with behavioral problems (Helland et al., 2014), children with DS (Udhnani et al., 2020), and children with ASD (Levinson, Eisenhower, Bush, Carter \& Blancher, 2020; Norbury, Gemmell \& Paul, 2013). Pragmatic communication ability also was significantly related to behavior and emotion regulation for both groups of children. This pattern has been reported previously 
for children with DS (Lee et al., 2017), children with ASD or SLI (Geurts \& Embrechts, 2008; Helland \& Helland, 2017), children with behavior problems (Helland et al., 2014), and TD children (Leonard et al., 2011).

Finally, for children with WS but not for children with Dup7, pragmatic communication ability was significantly related to nonverbal reasoning ability. This mixed finding is congruent with the current literature. A relation between pragmatic communication and nonverbal reasoning has been found in children with ASD (Udhnani et al., 2020), and children with DS (Lee et al., 2017) while other studies do not find the relationship in children with DS (Udhnani et al., 2020) typically developing children, or children with ASD (Whyte \& Nelson, 2015).

\section{Concurrent Predictors}

For children with WS, language form and content ability, behavior and emotional regulation, $\mathrm{CA}$, and sex all contributed significantly to the model predicting concurrent pragmatic communication ability. Language form and content was the strongest predictor, with better language form and content ability predicting better pragmatic communication. Behavioral and Emotional Regulation was the next strongest predictor, with better regulation predicting stronger pragmatic communication. CA and Sex were significant but weak predictors of pragmatic communication, with girls evidencing stronger pragmatic communication than boys and younger CA being associated with higher mean scaled score for Pragmatic Communication. Although as children with WS increase in CA their raw pragmatic communication scores also increase, the gains are not large enough to keep the scaled score constant. 
For children with Dup7, the pattern was the same for children with WS except that Sex was not a significant predictor of pragmatic communication. It is likely this is due to power; both the semi-partial correlation and Cohen's $f^{2}$ values for Sex for the Dup7 group were similar to those for the WS group.

Similar findings have been reported in other studies. Lane and colleagues (2019) also found language form and content and CA predicted pragmatic communication for both children with WS and children with Sotos syndrome. In their study which included smaller sample sizes than the present study, sex was not a significant predictor for either syndrome. In addition, in children with behavior problems, language form and content ability and extent of behavior problems at 7 years of age predicted pragmatic communication ability at ages $12-15$ years old (Helland et al., 2014).

Behavioral and emotional regulation was also a significant predictor of pragmatic communication for both syndromes. The BRIEF-2 BRI and ERI measure the ability to inhibit one's prepotent responses, shift between cognitive sets, exert emotional regulation, and monitor one's own behaviors while maintaining control of one's emotional response. No study has previously been done relating behavioral and emotional regulation to pragmatic communication in children with WS or Dup7. However, in other syndromes executive functioning has been shown to predict pragmatic communication. Udhnani and colleagues (2019) found that a model including sex, nonverbal IQ, social abilities, and executive functioning predicted pragmatic language in children with ASD or DS, although they did not report which of these variables contributed significant unique variance to pragmatic communication ability. 
CA also was a significant predictor of pragmatic communication for both syndromes. This also confirms the previous findings for children and adults with ASD (Wallace et al., 2018) and children with DS (Lee et al., 2018) that CA predicts pragmatic communication.

Sex was a significant predictor of pragmatic communication for children with WS but not for children with Dup7. The WS finding is consistent with Wallace and colleagues (2018) who found sex was predictive of pragmatic language ability in children with ASD. For the Dup7 group, the lack of a significant effect for sex was likely due to limited power, as both the part correlation and Cohen's $f^{2}$ for the effect of Sex were similar to those for the WS group.

Nonverbal ability did not provide a significant contribution to the model for WS or Dup7. This replicates a previous study that did not find nonverbal ability to correlate with pragmatic communication ability in children with ASD or TD controls (Norbury et al., 2013).

\section{Potential Gene Dosage Effects}

The findings from this study provide evidence for at least three clear effects of gene dosage for one or more genes in the WS region of chromosome 7q11.23 on language/cognitive ability. Relative to TD children, children with WS and children with Dup7 demonstrated a significant difficulty both with language form and content and with pragmatic communication as measured by the CCC-2. This pattern is indicative of a gene dosage effect in which any variation in gene dosage negatively affects an ability (Deshpande, \& Weiss, 2018). However, the overall negative effect on everyday language and communication was significantly larger for Dup7 than for WS, indicating that 
duplication of one or more of the genes in the WS region is more deleterious than deletion for these components of the phenotype. This effect was especially apparent for speech articulation, both as measured by the CCC-2 in the present study and by the examiner-administered GFTA-2 as reported by Huffman (2019). For overall intellectual ability, both deletion and duplication of one or more genes in the WS region again had a negative effect. However, in this case, deletion was more deleterious than duplication, as overall IQ was considerably higher for children with Dup7 than for children with WS,

\section{Limitations and Future Directions}

Dup7 is a more recently genotyped syndrome (Somerville et al., 2005) and while the sample included in this study is among the largest for children with this syndrome, it is considerably smaller than the sample of children with WS. To determine the generalizability of the present findings, similar studies should be conducted with children who have other syndromes.

In the present study, only the CCC-2 caregiver form was used. Another perspective would be to include the teacher report form along with the parent report form in future studies. Hammond (2019) found that the parent and the teacher forms only demonstrated poor to fair agreement for children with developmental language disorders; however, the two did agree on whether there was a social communication problem present. In addition, an observational lab measure, such as the Pragmatic Protocol (Prutting \& Kirchner, 1987) could have been included to measure communication ability in the lab. However, the use of the CCC-2, which is widely accepted as a measure of pragmatic communication, allows for a broader inclusion of real-world situations. The same limitations are present for the use of the BRIEF-2 for measuring executive 
functioning skills. There are parent report measures of executive functioning and experimenter-administered tasks of executive functioning skills. However, the use of the BRIEF-2 allowed for a measure of various aspects of real-world executive functioning such as emotional regulation and behavioral regulation which would be more difficult to measure in a laboratory task.

The current study was cross-sectional. To determine the developmental trajectory of language form and content ability and pragmatic communication ability more accurately, longitudinal studies are needed. To begin to narrow down which of the genes in the WS region is contributing to reductions in language form and content ability, pragmatic communication ability, speech articulation, and overall intellectual ability, studies comparing the rare children with shorter deletions or duplications of the WS region are needed.

\section{Summary and Conclusion}

In the present dissertation I sought to examine the overall level of language and communication ability as measured by the CCC-2 for children with WS and children with Dup7, to determine the pattern of relative strengths and weaknesses in language form and content, pragmatic communication, and ASD-related behaviors for both WS and Dup7, and to determine concurrent predictors of pragmatic communication for the two syndromes. Difficulty with overall language performance was demonstrated for both syndromes. However, as evidenced by their SIDI scores, children with WS and children with Dup7 on average performed at the same level for pragmatic communication as for language form and content, which is the same pattern as for the general population. On the Form and Content scales, children with WS had the most difficulty on Coherence, 
whereas children with Dup7 had the most difficulty on the Speech scale. Within Pragmatic Communication, both groups evidenced a relative weakness on Initiation. Children with WS also evidenced a relative weakness on Use of Context, whereas the children with Dup7 also evidenced a relative weakness on Scripted Language. The two syndromes demonstrated opposing patterns on the Autism-related scales: Children with WS showed a relative strength on Social Relations whereas children with Dup7 showed a relative strength on Interests. The concurrent predictors of pragmatic communication ability were very similar for the two syndromes, with significant effects for language form and content ability, behavior and emotional regulation, and CA. Interventions that focus on improving language form and content ability and interventions focused on emotional and behavioral regulation may be beneficial in improving the pragmatic communication abilities of children with WS and children with Dup7. Finally, the results of this dissertation contribute to an improved understanding of potential gene dosage effects of one or more genes in the WS region on chromosome 7q11.23 on language and communication abilities. 


\section{REFERENCES}

Adams, C. (2001). Clinical diagnostic and intervention studies of children with a semantic-pragmatic language disorder. International Journal of Language \& Communication Disorders, 36, 289 - 305. doi: 10.1080/1368282011005516 1

Ash, A. C., Redmond, S. M., Timler, G. R., \& Kean, J. (2017). The influence of scale structure and sex on parental reports of children's social pragmatic communication symptoms. Clinical Linguistics \& Phonetics, 31, 293 - 312. doi: $10.1080 / 02699206.1257655$

Bellugi, U, Marks, S, Bihrle, A, \& Sabo, H. (1988). Dissociation between language and cognitive functions in Williams syndrome. In D. Bishop \& K. Mogford (Eds.), Language development in exceptional circumstances (pp. 177-189). London: Churchill Livingstone.

Becerra, A. M., \& Mervis, C. B. (2019). Age at onset of declarative gestures and 24month expressive vocabulary predict later language and intellectual abilities in young children with Williams syndrome. Frontiers in Psychology, 10:2648. doi: 10.3389/fpsyg.2019.02648

Bignell, S., \& Cain, K. (2007). Pragmatic aspects of communication and language comprehension in groups of children differentiated by teacher ratings of inattention and hyperactivity. British Journal of Developmental Psychology, 25, 499 - 452. doi: 10.1348/026151006X171343 
Bishop, D. V. M. (1998). Development of the Children's Communication Checklist (CCC): A method for assessing qualitative aspects of communicative impairment in children. Journal of Child Psychology and Psychiatry, 39, 879 - 891.

Bishop, D. V. M. (2003). Children's Communication Checklist-2 (CCC-2). London: Psychological Corporation.

Bishop, D. V. M. (2006). Children's Communication Checklist-2, (CCC-2), United States edition manual. San Antonio, TX: Pearson.

Bishop, D.V., \& Baird, G. (2001). Parent and teacher report of pragmatic aspects of communication: use of the Children's Communication Checklist in a clinical setting. Developmental Medicine and Child Neurology. 43, 809-818. doi: 10.1017/s0012162201001475

Bloom, L., \& Lahey, M. (1978). Language development and language disorders. New York: Wiley.

Broeders, M., Geurts, H., \& Jennekens-Schinkel, A. (2010). Pragmatic communication deficits in children with epilepsy. International Journal of Language \& Communication Disorders, 45, 608-616.

https://doi.org/10.3109/13682820903374246

Carney, D. P., Brown, J. H., \& Henry, L. A. (2013). Executive function in Williams and Down syndromes. Research in Developmental Disabilities, 34, 46-55. doi: $10.1016 /$ j.ridd .2012 .07 .013

Carrow-Woolfolk, E. (1999). Comprehensive Assessment of Spoken Language. Circle Pines, MN: American Guidance Service. 
Davies, M., Udwin, O., \& Howlin, P. (1998). Adults with Williams syndrome. A preliminary study of social, emotional, and behavioral difficulties. British Journal of Psychiatry, 172, 273-276. doi: 10.1192/bjp.172.3.273

Deshpande, A., \& Weiss, L.A. (2018). Recurrent reciprocal copy number variants: Roles and rules in neurodevelopmental disorders. Developmental Neurobiology, 78, 519-530. doi: 10.1002/dneu.22587.

Dewart, H., \& Summers, S., (1995), The Pragmatics Profile of Everyday Communication Skills in Children. Windsor: NFER-Nelson.

Dilts, C. V., Morris, C. A., \& Leonard, C. O. (1990). Hypothesis for development of a behavioral phenotype in Williams syndrome. American Journal of Medical Genetics Supplement, 6, $126-131$.

Dunn, L. E., \& Dunn, D. M. (2007). Peabody Picture Vocabulary Test-4. Minneapolis, MN: Pearson Assessments.

Earhart, B. A., Williams, M. T., Zamura, L., Randolf, L.M., Cotava-Smith, J. K., \& Marcy, S. N. (2017). The phenotype of 7q11.23 duplication: A family clinical series. American Journal of Medical Genetics Part A, 173, 114 - 119. doi: 0.1002/ajmg.a.37966.

Elliott, C. D. (2007). Differential Ability Scales, $2^{\text {nd }}$ edition. San Antonio, TX: Psychological Corporation.

Fidler, D., Hepburn, S., Most, D., Philofsky, A., \& Rogers, S. (2007). Emotional responsivity in young children with Williams syndrome. American Journal of Mental Retardation, 112, 194-206. doi: 10.1352/0895-8017. 
Fombonne, E. (2009). Epidemiology of pervasive developmental disorders. Pediatric Research, 65, 591-598. https://doi.org/10.1203/PDR.0b013e31819e7203.

Geurts, H. M., \& Embrechts, M. (2008). Language profiles in ASD, SLI, and ADHD. Journal of Autism and Developmental Disorders, 38, 1931 - 1943. doi: $10.1007 / \mathrm{s} 10803-008-0587-1$

Gioia, G. A., Isquith. P. K., Guy, S. C., \& Kenworthy, L. (2000). BRIEF: Behavior Rating Inventory of Executive Function. Lutz, FL: Psychological Assessment Resources.

Gioia, G. A., Isquith P. K., Guy, S. C., \& Kenworthy, L. (2015). BRIEF-2: Behavior Rating Inventory of Executive Function, second edition. Lutz, FL. Psychological Assessment Resources.

Goldman, R., \& Fristoe, M. (2000). The Goldman-Fristoe Test of Articulation ( $2^{\text {nd }}$ ed.). Circle Pines, MN: American Guidance Service.

Goodman, R. (1997). The Strengths and Difficulties Questionnaire: a research note. Journal of Child Psychology and Psychiatry, 38, 581-586. doi: 10.1111/j.1469-7610.1997.tb01545.x.

Gosch, A., \& Pankau, R. (1997). Personality characteristics and behavior problems in individuals of different ages with Williams syndrome. Developmental Medicine and Child Neurology, 39, 527-533.

Gresham, F. M., \& Elliott, S. N. (1990). Social Skills Rating System manual. Circle Pines, MN: American Guidance Service.

Hammond, C. L. (2019). Agreement between parent and teacher ratings of social communication abilities on the Children's Communication Checklist-second edition. Theses and Dissertations. https://scholarsarchive.byu.edu/etd/7485 
Helland, A. H., \& Helland, T. (2017). Emotional and behavioral needs in children with specific language impairment and children with autism spectrum disorder: The importance of pragmatic language impairment. Research in Developmental Disabilities, 70, 33 - 39. doi: 10.1016/j.ridd.2017.08.009

Helland, W. A., Lundervold, A., Heimann, M., \& Posserud, M. (2014). Stable associations between behavioral problems and language impairments across childhood. The importance of pragmatic language problems. Research in Developmental Disabilities, 35, 943 - 951. doi: 10.1016/j.ridd/2014.02.016

Hillier, L.W., Fulton, R. S., Fulton, L. A., Graves, T. A., Pepin, K.H., Wagner-McPherson, C., ... Wilson, R. K. (2003). The DNA sequence of human chromosome 7. Nature, 424(6945), 157-164. doi: 10.1038/nature01782

Hoffmann, A., Martens, M. A., Fox, R., Rabidoux, P., \& Andridge, R. (2013). Pragmatic language assessment in Williams syndrome: A comparison of the Test of Pragmatic Language-2 and the Children's Communication Checklist-2. American Journal of Speech-Language Pathology, 22, 198 - 204. doi: 10.1044/1058-0360

Huffman, M. J. F., (2019). Speech articulation in children with Williams syndrome or $7 q 11.23$ duplication syndrome. Electronic Theses and Dissertations. University of Louisville, Paper 3242. https://doi.org/10.18297/etd/3242

Hyter, Y. D., Rogers-Adkinson, D. L., Self, T. L., Simmons, B. F., \& Jantz, J. (2001). Pragmatic language intervention for children with language and emotional/behavioral disorders. Communication Disorders Quarterly, 23, 4-16. http://dx.doi.org/10.1177/152574010102300103. 
Kaufman, A. S., \& Kaufman, N. L. (2004). Kaufman Brief Intelligence Test, second edition. Circle Pines, MN: American Guidance Services.

Ketelaars, M. P., Cuperus, J., Jasonius, K., \& Verhoeven, L. (2010). Pragmatic language impairment and associated behavioral problems. International Journal of Language and Communication Disorders, 45, $204-214$. doi: $10.3109 / 13682820902863090$

Klein-Tasman, B. P., Li-Barber, K. T., \& Magargee, E. T. (2011). Honing in on the social phenotype in Williams syndrome using multiple measures and multiple raters. Journal of Autism and Developmental Disorders, 41, 341-351.

Klein-Tasman BP, Mervis CB. Distinctive personality characteristics of 8-, 9-, and 10year-olds with Williams syndrome. Developmental Neuropsychology, 23,269-290. doi: $10.1080 / 87565641.2003 .9651895$.

Klein-Tasman, B. P., Mervis, C. B., Lord, C., \& Phillips, K. D. (2007). Sociocommunicative deficits in young children with Williams syndrome: performance on the Autism Diagnostic Observation Schedule. Child Neuropsychology, 13, 444467. doi:10.1080/09297040601033680.

Klein-Tasman, B. P., van de Fluit, F., \& Mervis, C. B. (2018). Autism spectrum symptomatology in children with Williams syndrome who have phrase speech or fluent language. Journal of Autism and Developmental Disorders, 48, 3037 3050. doi.org/10.1007/s10803-018-3555-4

Janes, E., Riby, D. M., \& Rodgers, J. (2014). Exploring the prevalence and phenomenology of repetitive behaviors and abnormal sensory processing in 
children with Williams syndrome. Journal of Intellectual Disability Research, 58, 746 - 757. doi.org/10.1111/jir.12086

John, A. E., Dobson, L. A., Thomas, L. E., \& Mervis, C. B. (2012). Pragmatic abilities of children with Williams syndrome: A longitudinal examination. Frontiers in Psychology, 3:199. doi: 10.3389/fpsyg.2012.00199

John, A. E., \& Mervis, C. B. (2010). Sensory modulation impairments in children with Williams syndrome. American Journal of Medical Genetics Part C (Seminars in Medical Genetics), 154C, 266-276. doi: 10.1002/ajmg.c.30260.

John, A. E., Rowe, M. L., \& Mervis, C. B. (2009). Referential communication skills of children with Williams syndrome: Understanding when messages are not adequate. American Journal on Intellectual and Developmental Disabilities, 114, $85-99$.

Laing, E., Butterworth, G., Ansari, D., Gsödl, M., Longhi, E., Panagiotaki, G., Paterson, S., \& Karmiloff-Smith, A. (2002). Atypical development of language and social communication in toddlers with Williams syndrome. Developmental Science, 5, 233-246. https://doi.org/10.1111/1467-7687.00225

Landa, R. J. (2005). Assessment of social communication skills in preschoolers. Mental Retardation and Developmental Disabilities Research Reviews, 11, 247-252. doi: $10.1002 / \mathrm{mrdd} .20079$

Lane, C., van Herwegen, J., \& Freeth, M. (2019). Parent-reported communication abilities of children with Sotos syndrome: Evidence from the Children's Communication Checklist-2. Journal of Autism and Developmental Disorders,49, 1475-1483. doi. 10.1007/s10803-018-3842-0 
Lapadat, J. (1991). Pragmatic language skills of students with language and/or learning disabilities: A quantitative synthesis. Journal of Learning Disabilities, 24, 147 158.

Laws, G., \& Bishop, D. (2003). A comparison of language abilities in adolescents with Down syndrome and children with specific language impairment. Journal of Speech, Language, and Hearing Research, 46, 1324 - 13229. doi.org/10.1044/1092-4388(2003/103)

Laws, G., \& Bishop, D. (2004). Pragmatic language impairment and social deficits in Williams syndrome: a comparison with Down's syndrome and specific language impairment. International Journal of Language \& Communication Disorders, 39 , 45-64. doi: 10.1080/13682820310001615797

Lee, M., Bush, L., Martin, G. E., Barstein, J., Maltman, N., Klusek, J., \& Losh, M. (2017). A multimethod investigation of pragmatic development in individuals with Down syndrome. American Journal on Intellectual and Developmental Disabilities, 122, 289 - 309. doi: 10.1352/1944-7558-122.4.289

Lee, N. R., Godfrey, M., Hanmer, T., Perez, M. Carolin, A., Adeyemi, E., Clasen, L. S., \& Giedd, J. N. (2018, April). Executive correlates of structural and pragmatic language in youth with DS: Evidence from an informant and performance-based measures. Gatlinburg Conference on Research and Theory in Intellectual and Developmental Disabilities, San Diego, CA.

Leonard, M. A., Milich, R., \& Lorch, E. P. (2011). The role of pragmatic language use in mediating the relation between hyperactivity and inattention and social skills 
problems. Journal of Speech, Language and Hearing Research, 54, 567 - 579. doi: $10.1044 / 1092-4388$

Levinson, S., Eisenhower, A., Bush, H. H., Carter, A. S., \& Blacher, J. (2020). Brief report: predicting social skills from semantic, syntactic, and pragmatic language among young children with autism spectrum disorder. Journal of Autism and Developmental Disorders, 50, 4165-4175. https://doi.org/10.1007/s10803-020-04445-z

Leyfer, O. T., Woodruff-Borden, J., Klein-Tasman, B. P., Fricke, J. S., \& Mervis, C. B. (2006). Prevalence of psychiatric disorders in 4 to 16-year-olds with Williams syndrome. American Journal of Medical Genetics Part B: Neuropsychiatric Genetics, 141B, 615-622.

Lord, C., Rutter, M., DiLavore, P. C., Risi, S., Gotham, K., \& Bishop, S. L. (2012). Autism Diagnostic Observation Schedule (2nd ed.). Los Angeles, CA: Western Psychological Services.

Mervis, C. B. (2006). Language abilities in Williams-Beuren syndrome. In C. A. Morris, H. M. Lenhoff, \& P. P. Wang (Eds.), Williams-Beuren syndrome: Research, evaluation, and treatment (pp. 159-206). Baltimore, MD: Johns Hopkins University Press.

Mervis C. B. (2009). Language and literacy development of children with Williams syndrome. Topics in Language Disorders, 29, 149-169. https://doi.org/10.1097/TLD.0b013e3181a72044

Mervis, C. B., \& Greiner de Magalhães, C. (in press). Williams syndrome. In M. Beauchamp, R. Peterson, M. D. Ris, H. G. Taylor, \& K. O. Yeates (Eds.). 
Pediatric neuropsychology: Research, theory, and practice, 3rd ed. New York: Guilford.

Mervis, C. B., \& John, A. E. (2010). Cognitive and behavioral characteristics of children with Williams syndrome: Implications for intervention approaches. American Journal of Medical Genetics Part C: Seminars in Medical Genetics, 154C, 229248. doi: 10.1002/ajmg.c.30263.

Mervis, C. B., Klein-Tasman, B. P., Huffman, M. J., Velleman, S. L., Pitts, C. H., Henderson, D.R., ... Osborne, L. R. (2015). Children with 7q11.23 duplication syndrome: Psychological characteristics. American Journal of Medical Genetics A, 167A, 1436-1450. doi: 10.1002/ajmg.a.37071

Mervis, C. B., Robinson, B. F., Bertrand, J., Morris, C. A., Klein-Tasman, B. P, \& Armstrong, S. C. (2000). The Williams syndrome cognitive profile. Brain and Cognition, 44, 604-628. https://doi.org/10.1006/brcg.2000.1232

Morris, C. A. (2006). The dysmorphology, genetics, and natural history of WilliamsBeuren syndrome. In C. A. Morris, H. M. Lenhoff, \& P. P. Wang (Eds.). WilliamsBeuren syndrome: Research, evaluation, and treatment (pp. 3-17). Baltimore, MD: Johns Hopkins University Press.

Morris, C. A., Mervis, C. B., Paciorkowski, A. P., Abdul-Rahman, O., Dugan, S. L., Rope, A. F., . . Osborne, L. R. (2015). 7q11.23 duplication syndrome: Physical characteristics and natural history. American Journal Medicine and Genetics Part A, 167A, 2916-2935. doi: 10.1002/ajmg.a.37340

Mullen, E. (1995). Mullen Scales of Early Learning. Circle Pines, MN: American Guidance Systems. 
Meyerson, M. D., \& Frank, R. A. (1987). Language, speech, and hearing in Williams syndrome: Intervention approaches and research needs. Developmental Medicine \& Child Neurology, 29, 258-270.

Norbury, C. F., Gemmell, T., \& Paul, R. (2013). Pragmatic abilities in narrative production: A cross-disorder comparison. Journal of Child Language, 41, 485 510. doi: 0.1017/S030500091300007X

Norbury, C. F., \& Holloway, R. (2014). Practitioner review: Social (pragmatic) communication disorder conceptualization, evidence, and clinical implications. Journal of Child Psychology and Psychiatry, 55, 204-216. doi:10.1111/jcpp.12154

Norbury, C. F., Nash, M., Baird, G., \& Bishop, D. V. M. (2004). Using a parental checklist to identify diagnostic groups in children with communication impairment: a validation of the Children's Communication Checklist-2. International Journal of Language \& Communication Disorders, 39, 345-364, doi: $10.1080 / 13682820410001654883$

Parsons, L., Cordier, R., Munro, N., Joosten, A., Speyer, R. (2017). A systematic review of pragmatic language interventions for children with autism spectrum disorder. PLoS ONE, 12. https://doi.org/10.1371/journal.pone.0172242

Pérez-García, D., Brun-Gasca, C., Pérez-Jurado, L. A., \& Mervis, C. B. (2017). Behavioral profiles of children with Williams syndrome from Spain and the United States: Cross-cultural similarities and differences. American Journal on Intellectual and Developmental Disabilities, 122, 156-172. doi: 10.1352/1944-7558-122.2.156. 
Philofsky, A., Fidler, D. J., \& Hepburn, S. (2007). Pragmatic language profiles of schoolage children with autism spectrum disorders and Williams syndrome. American Journal of Speech and Language Pathology, 16, 368-380.

Pitts, C. H., Klein-Tasman, B. P., Osborne, J. W., \& Mervis, C. B. (2016). Predictors of specific phobia in children with Williams syndrome. Journal of Intellectual Disability Research, 60, 1031 - 1042. doi:10.1111/jir.12327

Pijnacker, J., Vervloed, M. P. J., \& Steenbergen, B. (2012). Pragmatic abilities in children with congenital visual impairment: An exploration of non-literal language and advanced theory of mind understanding. Journal of Autism and Developmental Disorders, 42, 2440 - 2449. doi: 10.1007/s10803-012-1500-5

Prutting, C. A., \& Kirchner, D. M. (1987). A clinical appraisal of the pragmatic aspects of language. Journal of Speech and Hearing Disorders, 52, 105-119.

Rodas, N.V., Eisenhower, A. \& Blacher, J. (2017). Structural and pragmatic language in children with ASD: Longitudinal impact on anxiety and externalizing behaviors. Journal of Autism and Developmental Disordders, 47, 3479-3488. https://doi.org/10.1007/s10803-017-3265-3

Rodgers, J., Riby, D. M., Janes, E., Connolly, B., \& McConachie, H. (2012). Anxiety and repetitive behaviours in autism spectrum disorders and Williams syndrome: A cross-syndrome comparison. Journal of Autism and Developmental Disorders, 42, 175-180. doi: 10.1007/s10803-011-1225-x.

Semel, E., \& Rosner, S. R. (2003). Understanding Williams syndrome: Behavioral patterns and interventions. Mahwah, NJ: Lawrence Erlbaum. 
Semel, E., Wiig, E., \& Secord, W. A. (2013). Clinical Evaluation of Language Fundamentals (4th ed.). San Antonio, TX: Pearson.

Smith, E., Næss, K.B., \& Jarrold, C. (2017) Assessing pragmatic communication in children with Down syndrome. Journal of Communication Disorders, 68, 10-23. doi: 10.1016/j.jcomdis.2017.06.003.

Somerville, M. J., Mervis, C. B., Young, E. J., Seo, E.-J., del Campo, M., Bamforth, S., . . Osborne, L. R. (2005). Severe expressive language delay related to duplication of the Williams-Beuren locus. New England Journal of Medicine, 353, 16941701.

Spanoudis, G., Natsopoulos, D., \& Panayiotou, G. (2007). Mental verbs and pragmatic language difficulties. International Journal ofLanguage \& Communication Disorders, 42, 487-504. doi: 10.1080/13682820601010027.

Stojanovik V. (2006). Social interaction deficits and conversational inadequacy in Williams syndrome. Journal of Neurolinguistics, 19, 157 - 173. doi: 10.1016/j.jneuroling.2005.11.005

Stojanovik, V., Perkins, M., \& Howard, S. (2001). Language and conversational abilities in Williams syndrome: how good is good? International Journal of Language \& Communication Disorders, 36 (Suppl.), 234-239.

Strømme P., Bjørnstad, P. G., \& Ramstad, K. (2002). Prevalence estimation of Williams syndrome. Journal of Child Neurology, 17, 269 - 271.

Sullivan, K., Winner, E., \& Tager-Flusberg, H. (2003). Can adolescents with Williams syndrome tell the difference between lies and jokes? Developmental Neuropsychology, 23, $85-103$. 
Tager-Flusberg, H. \& Sullivan, K. (2000). A componential view of theory of mind: evidence from Williams syndrome. Cognition, 76, 59-89.

Tager-Flusberg, H., Sullivan, K., \& Boshart, J. (1997). Executive functions and performance on false belief tasks, Developmental Neuropsychology, 13, 487-493. doi: $10.1080 / 87565649709540689$

Timler, G. R. (2014). Use of the Children's Communication Checklist-2 for classification of language impairment risk in young school-age children with attentiondeficit/hyperactivity disorder. American Journal of Speech-Language Pathology, 23, 73-83. doi: 10.1044/1058-0360

Tomc, S.A., Williamson, N.K., Pauli, R.M. (1990). Temperament in Williams syndrome. American Journal of Medical Genetics, 36, 345-352. doi: 10.1002/ajmg.1320360321.

Udhnani, M., Maiman, M., Blumenthal, J., Clasen, L. S., Giedd, J. N., Razhahan, A., \& Lee, N. R. (2018, April). Parent ratings of behavioral regulation and metacognition and their relation to structural and pragmatic language in youth with sex chromosome trisomies. Gatlinburg Conference on Research and Theory in Intellectual and Developmental Disabilities, San Diego, CA.

Udhnani, M., P., Pereza, M., Clasen, L. S., Adeyemic, E., \& Lee, N. R. (2020). Relations between everyday executive functioning and language in youth with Down syndrome and youth with autism spectrum disorder. Developmental Neuropsychology. 45, 79 - 93. doi: 10.1080/87565641.2019.1706518

Udwin, O., \& Yule, W. (1990). Expressive language of children with Williams syndrome. American Journal of Medical Genetics Supplement, 6, 108-114. 
Udwin, O., Yule, W., \& Martin, N. (1987). Cognitive abilities and behavioural characteristics of children with idiopathic infantile hypercalcaemia. Journal of Child Psychology and Psychiatry, 28, 297-309.

Van der Aa, N., Rooms, L., Vandeweyer, G., van den Ende, J., Edwin, R.,... Koy, R. F. (2009). Fourteen new cases contribute to the characterization of the $7 q 11.23$ microduplication syndrome. European Journal of Medical Genetics, 52, 94 100. doi: 10.1016/j.ejmg.2009.02.006.

Velleman, S. L., \& Mervis, C. B. (2011). Children with 7q11.23 duplication syndrome: Speech, language, cognitive and behavioral characteristics and their implications for intervention. Perspectives on Language Learning and Education, 18, 108116. doi:10.1044/1le18.3.108.

Volden, J., \& Phillips, L. (2010). Measuring pragmatic language in speakers with autism spectrum disorders: Comparing the Children's Communication Checklist-2 and the Test of Pragmatic Language. American Journal of Speech-Language Pathology, 19, 204 - 212. doi:10.1044/1058-0360

Wallace, G. L., Crutcher, J. Armour, A. C., Martin, A., \& Kenworthy, L. (2018, April). Associations between real-world executive functions and both structural and pragmatic language among children and adults with ASD. Gatlinburg Conference on Research and Theory in Intellectual and Developmental Disabilities, San Diego, CA.

Washburn, G. N. (2011). Using situational comedies for pragmatic language teaching and learning. TESOL, 10(4), 21-26. doi: 10.10021j.1949-3533.2001.tb00045.x 
Werling, D. M., \& Geschwind, D. H. (2013). Understanding sex bias in autism spectrum disorder. Proceedings of the National Academy of Sciences of the United States of America, 110, 4868-4869. https://doi.org/10.1073/pnas.1301602110.

Whyte, E. M. \& Nelson, K. E. (2015). Trajectories of pragmatic and nonliteral language development in children with autism spectrum disorders. Journal of Communication Disorders, 54, 2-14. doi.org/10.1016/j.jcomdis.2015.01.001.

Williams, K. T. (2007). Expressive Vocabulary Test, $2^{\text {nd }}$ edition. Minneapolis, MN: Pearson Assessments. 


\title{
CURRICULUM VITAE
}

\section{Personal Information:}

\author{
Amanda G. Harmon
}

Office Address:

\author{
Charleston Southern University \\ 101 Strom Thurmond Faculty Suites \\ 9200 University Boulevard \\ Charleston, SC 29406 \\ 843-863-7712 \\ aharmon@csuniv.edu \\ amanda.harmon@1ouisville.edu
}

Office phone Number:

Email address:

\section{Education:}

University of Louisville

Louisville, KY

Ph.D., Experimental Psychology

2020

University of Louisville

Louisville, KY

M.S., Experimental Psychology

2011

The Pennsylvania State University

University Park, PA

M.S., Biobehavioral Health

2008

2007-2008 Hintz Graduate Education Enhancement Award

The Pennsylvania State University

University Park, PA

B.A., Human Development and Family Studies

2006

American Association of University Women Grant

Stuart Ellen Scholarship

\section{Professional History}

Assistant Professor of Psychology

Charleston Southern University

August 2017 - present

Certified Online Instructor 2019

Quality Matters Course Reviewer

Spring 2018 - present

Adjunct Instructor

Charleston Southern University

August 2016 - July 2017 
Statewide Trainer and Compliance Officer

Adjunct Instructor

Adjunct Instructor

Graduate Research Assistant

Teaching Assistant
JusticeWorks BehavioralCare

May 2013 - August 2017

Eastern University, PA

Spring 2013

The Pennsylvania State University

Summer 2006, Summer 2007

University of Louisville,

Neurodevelopmental Science Laboratory

July 2008 - June 2012

The Pennsylvania State University

Spring 2005 - Spring 2008

\section{$\underline{\text { Publications }}$}

Farwig, K., Harmon, A. G., Fontana, K. M., Mervis, C. B., \& Morris, C. A. (2010). Genetic counseling of adults with Williams syndrome: A first study. American Journal of Medical Genetics, 154C, 307-315.

Harmon, A. G., Towe-Goodman, N., Fortunato, C., \& Granger, D. (2008). Use of salivary alpha-amylase in biobehavioral research: A note of caution. Hormones and Behavior, 54, 592-596.

Harmon, A. G., Hibel, L. C., Rumyantseva, O., \& Granger, D. A., (2007). Measuring salivary cortisol in studies of child development: Watch out - what goes in may not come out of commonly used saliva collection devices. Developmental Psychobiology, $49,495-500$.

Granger, D. A., Kivlighan, K. T., Fortunato, C., Harmon, A. G., Hibel, L. C., Schwartz, E. B., \& Whembolua, G-L (2007). Integration of salivary biomarkers into developmental and behaviorally-oriented research: Problems and solutions for collecting specimens. Physiology and Behavior, 92, 583-590.

\section{Conference Presentations (Oral)}

Shivvers, A. \& Harmon, A. (2020, March). The effect of age on emotional intelligence adaptability, and relationship satisfaction. Southeastern Psychological Association, New Orleans, LA.

Blackmon, S. \& Harmon, A. (2020, April). The effect of checking for attention on survey participants' intuitive response. Carolinas Psychology Conference. Campbell University, Buies Creek, NC. 
Shivvers, A. \& Harmon, A. (2020, April). The relationship between emotional intelligence, adaptability, and relationship satisfaction. Carolinas Psychology Conference. Campbell University, Buies Creek, NC

Chenery, A. \& Harmon, A. (2019, April). The effects of social environmental factors on individuals' occupational and educational decision making. Carolinas Psychology Conference. Campbell University, Buies Creek, NC.

Rawls, G. \& Harmon, A. (2019, April). The effect of colorist views on attraction. Carolinas Psychology Conference. Campbell University, Buies Creek, NC.

\section{Conference Presentations (Poster)}

Blackmon, S. \& Harmon, A. (2020, March). The effect of checking for attention on survey participants' intuitive response. Southeastern Psychological Association, New Orleans, LA.

Bruner, A., \& Harmon, A. (2019, March). The effect of self-esteem on friendships and romantic relationships. Southeastern Psychological Association, Jacksonville, FL.

Shivvers, A., \& Harmon, A. (2019, March). Emotional intelligence in relation to strategic flexibility and relationship satisfaction. Southeastern Psychological Association, Jacksonville, FL.

Harmon, A. G., John, A. E., \& Mervis, C. B. (2010, June). Literacy skills of 9 - 17-yearolds with Williams syndrome: Impact of reading method. Symposium on Research in Child Language Disorders, Madison, WI.

Harmon, A. G., John, A. E., \& Mervis, C. B. (2009, June). Pragmatic language ability in children with Williams syndrome. Symposium on Research in Child Language Disorders, Madison, WI.

Harmon, A., Hibel, L. C., Rumyantseva, O., \& Granger, D. A., (2007, March). Measuring salivary cortisol in studies of child development: Watch out - what goes in may not come out of commonly used saliva collection devices. Biennial Meeting of the Society for Research in Child Development, Boston, MA.

Hibel, L. C., Harmon, A., \& Granger, D. A., \& Booth, A (2007, March). Salivary androstenedione and child development: Gender differences, pubertal development, age, and common salivary biomarkers. Biennial Meeting of the Society for Research on Child Development, Boston, MA. 